\title{
STRESS INTENSITY FACTORS OF TUBULAR T/Y-JOINTS SUBJECTED TO THREE BASIC LOADING
}

\author{
S.T. $\mathrm{Lie}^{1, *}, \mathrm{~T} . \mathrm{Li}^{1}$ and Y.B. Shao ${ }^{2}$ \\ ${ }^{1}$ School of Civil and Environmental Engineering, Nanyang Technological University, \\ 50 Nanyang Avenue, Singapore 639798 \\ ${ }^{2}$ School of Civil Engineering, Yantai University, Yantai City 264005, P. R. China \\ *(Corresponding author: E-mail: cstlie@ntu.edu.sg)
}

Received: 30 July 2014; Revised: 17 June 2015; Accepted: 3 July 2015

\begin{abstract}
This paper describes the determination of stress intensity factors (SIFs) of a 3D surface crack in a circular hollow section (CHS) T/Y-joint subjected to three basic loading. In order to achieve the main objective, an automatic finite element (FE) mesh generator is designed whereby the mesh density and element type of the Crack Tube zone can be controlled by the users. Extensive tests are carried out to check the accuracy and to test the convergence of the mesh models. It is found that the generated mesh models are both accurate and robust. Subsequently, a total of 246 cracked CHS T/Y-joints subjected to axial loading; in-plane bending and out-of-plane bending are analysed, and the influencing parameters $\beta, \gamma, \tau, \theta, a / t_{0}$ and $c / a$ on the SIFs of a 3D surface crack are investigated in this study. The SIFs at the deepest point of a 3D surface crack are also determined using an indirect method incorporated in BS7910. It is found that the later underestimates the SIFs by as much as $-36.9 \%$ under axial load for crack located at the crown and $-32.9 \%$ under out-of-plane bending for crack located at the saddle, respectively. Hence, the indirect method is found to be unsafe in estimating the SIFs of a 3D surface crack in CHS $\mathrm{T} / \mathrm{Y}$-joints under certain loading conditions and crack location.
\end{abstract}

Keywords: Finite element analysis, Mesh generation, 3D Surface crack, Stress intensity factor, Tubular T/Y-joint

DOI: 10.18057/IJASC.2016.12.2.3

\section{INTRODUCTION}

Stress intensity factor (SIF) is an important fracture parameter frequently used to estimate the fatigue life and to predict the fracture behaviour of a cracked component. As there are no analytical solutions available in the literature to determine the SIFs along the crack front of a 3D surface crack in a circular hollow section (CHS) joint, many researchers have to depend on the finite element (FE) method. The accuracy and convergence of the computed SIFs are influenced very much on the mesh quality of the generated FE mesh models particularly along the crack front and near the crack ends. It has a significant impact on the accuracy of the SIFs. For crack tips further away from the crack ends where the crack front intersects with the weld toe, SIFs can be determined accurately using $J$-integral and displacement extrapolation methods under the square root singularity assumption (Shivakumar and Raju [1], Madia et al. [2]). However, this is not the case for SIFs at the crack ends due to boundary layer effect. More evidence indicates that square root singularity assumption is not valid at the crack ends of a surface crack (Hutař and Náhlík [3], Heyder et al. [4]). Hence, both $J$-integral and displacement extrapolation methods cannot produce accurate SIFs exactly at the crack ends of a surface crack. The singularity at the crack ends of a surface crack is still being investigated by researchers (Madia et al. [2], Hutař and Náhlík [3], Heyder et al. [4]). Therefore, this study focus only on the calculation of SIFs at the crack tips farther away from the crack ends. 
For the past decades, many researchers had developed their special purpose automatic FE mesh generators (Huang and Hancock [5], Rhee [6], Bowness and Lee [7, 8], Cao et al. [9], Lie et al. [10], Chiew et al. [11]) as it is a daunting task to manually create the mesh models of the 3D surface crack in any CHS joint. Among of these researchers, Bowness and Lee [7, 8], Lie et al. [10] and Chiew et al. [11] had carried out extensive analyses on the SIFs of CHS T/Y-joints taking advantage of their own mesh generators. However, due to the limitations of their mesh generators, all the works done so far focus only on cracked CHS T-joints subjected to axial loading, and there are no published reports on SIFs of cracked CHS T/Y-joints subjected to in-plane bending and out-of-plane bending.

In addition to $\mathrm{FE}$ analyses, some researchers had carried out experimental tests on full-scale specimens to determine the SIFs of cracked CHS T-joints. Peter [12] carried out fatigue tests on high strength steel CHS T-joints under different axial loading. The crack propagation was monitored by the alternating current potential drop (ACPD) technique, and the SIFs at the deepest point were derived in conjunction with the Paris' crack propagation law. Shao and Lie [13] carried out similar fatigue tests on two full-scale CHS K-joints subjected to balanced axial loading and derived the SIFs using the same approach. In practice, it is very costly and time-consuming to carry out such large scale fatigue tests. Hence, it is not feasible to carry out extensive experimental tests to study the SIFs of cracked CHS T/Y-joints subjected to different loading cases.

Apart from numerical method and experimental test, there is an alternative method called the indirect method which can be used to calculate SIFs in a CHS joint. This indirect method has been incorporated in BS7910 [14], and it is based on a central cracked flat plate model subjected to tension and bending loading. The SIFs of a surface crack are calculated first by using the well-established Newman-Raju [15, 16] equation. Then, by incorporating the effects of the weld profile, local hot spot stress and local degree of bending (Lee and Bowness [17]), the flat plate model can be used to estimate the SIFs of any cracked CHS T/Y-joint containing a surface crack. Lie et al. [18] had applied it to CHS K-joints subjected to balanced axial loads, and found that it overestimates the SIFs by as much as $190.4 \%$ at the crack deepest point. This indirect method has not been tested extensively on CHS T/Y-joints subjected to in-plane bending and out-of-plane bending.

Hence, in this study, FE analysis is used to study the SIFs of cracked CHS T/Y-joints subjected under different loading conditions. A new FE mesh generator is developed to create the mesh models. Firstly, element types, mesh design of the surface crack front and mesh refinement schemes are presented. Secondly, the boundary conditions and loading types applied are introduced. Finally, mesh convergence test and verification of the FE mesh models are carried out. Subsequently, the

SIFs of 246 cracked CHS T/Y-joints subjected to three basic loading are calculated. The influencing parameters $\beta, \gamma, \tau, \theta, a / t_{0}$ and $c / a$ on the shape factors (dimensionless stress intensity factor) are investigated. Finally, the accuracy of the shape factors estimated using the indirect method incorporated in BS7910 [14] is examined and compared with the SIFs calculated using the present FE mesh models.

\section{GEOMETRY OF T/Y-JOINT}

Figure 1 shows the dimensionless parameters $\alpha, \beta, \gamma, \tau$, and $\theta$ of a CHS T/Y-joint subjected to three basic loading. If the angle $\theta$ is not equal to $90^{\circ}$, then the joint is considered as a Y-joint. It is common to group and denote such a T-joint and Y-joint as a T/Y-joint in practice. The range of geometries and crack shapes of the analyzed cracked CHS T/Y-joints are listed in Table 1 . The chord thickness of all the cracked CHS T/Y-joints is $10 \mathrm{~mm}$, and all the other parameters used to 
define the joint can be derived from Figure 1. The surface crack is located at the weld toe on the chord side of the hot spot stress location, and its value is obtained using the SCF equations recommended in API-RP-2A [19]. The Young's modulus and Poisson's ratio are $210 \mathrm{GPa}$ and 0.3, respectively

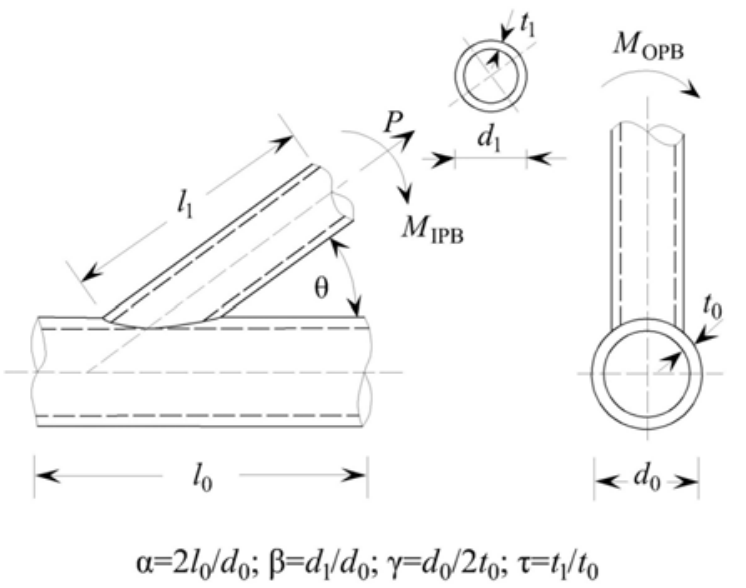

Figure 1. Geometry and Notations of a CHS T/Y-joint Subjected to Three Basic Loading

Table 1. Crack Shapes and Geometries of CHS T/Y-joints

\begin{tabular}{cccc}
\hline Group & 1 & 2 & 3 \\
\hline$\alpha$ & 14 & 24 & 14 \\
$\beta$ & $0.3 \sim 0.8$ & 0.8 & $0.3 \sim 0.8$ \\
$\gamma$ & $8 \sim 26$ & 8 & $8 \sim 26$ \\
$\tau$ & $0.4 \sim 1.0$ & 0.6 & $0.4 \sim 1.0$ \\
$\theta$ & $30^{0} \sim 90^{0}$ & $30^{0} \sim 90^{0}$ & $30^{0} \sim 90^{0}$ \\
$a / t_{0}$ & $0.2 \sim 0.8$ & $0.2 \sim 0.8$ & $0.2 \sim 0.8$ \\
$c / a$ & $3 \sim 10$ & $3 \sim 10$ & $3 \sim 10$ \\
Loading type & Axial, OPB & Axial & IPB \\
Crack location & Saddle & Crown & Crown \\
\hline
\end{tabular}

\section{FINITE ELEMENT MESH GENERATION}

In this section, FE mesh generation of cracked CHS T/Y-joints is introduced. Several important key points of the mesh generation are highlighted, including element types, mesh design of the surface crack front, and mesh refinement schemes. In addition, the double mapping approach used to generate FE mesh models of cracked CHS T/Y-joints is also briefly introduced in this section.

\subsection{Element Selection}

There are two types of solid elements, i.e. 20-nodes hexahedron and 15-nodes collapsed prism elements are used and shown in Figure 2. For the 15-nodes collapsed prism element, the middle nodes at element edges intersecting with the crack front are moved to the quarter position to produce the square root singularity. The collapsed prism elements are only used along the surface crack front. 


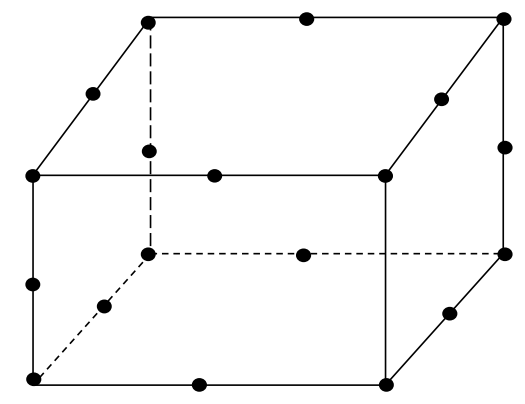

20-nodes hexahedron element

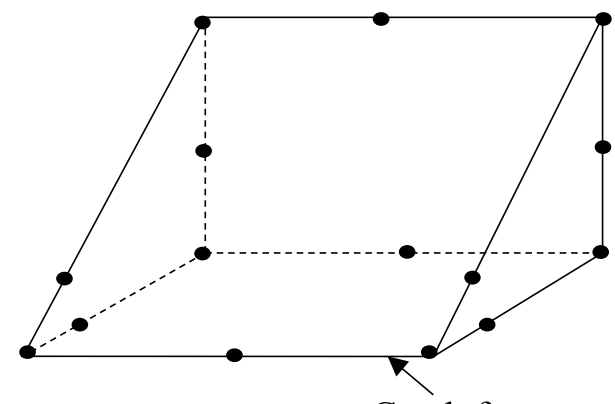

Crack front

15-nodes collapsed prism element

Figure 2. Solid Elements Used in FE Mesh Models

\subsection{Mesh Generation}

The surface crack block containing the crack front is generated by double mapping a 2D plain surface crack as shown in Figure 3. It can be seen that the zone is divided into three parts, including Part A, Part B and Crack Tube where the crack front is located.

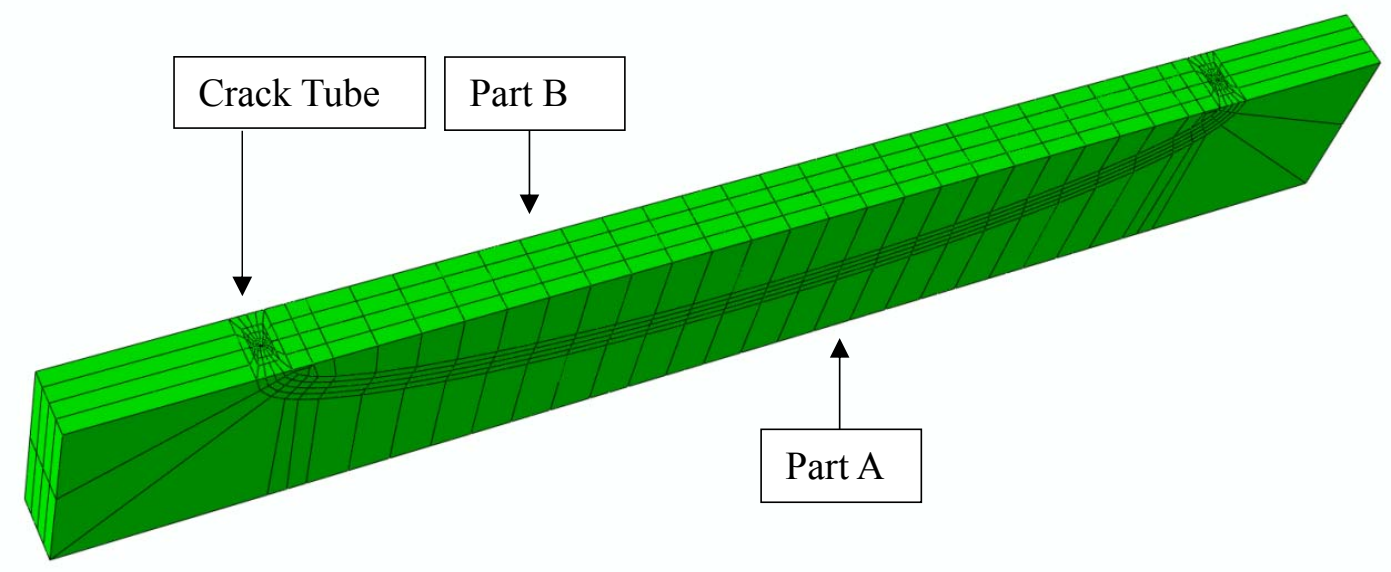

Figure 3. Mesh Design of the 2D Surface Crack Block in a Central Cracked Plain Plate

Figure 4 shows the internal mesh design by cutting a cross-section through the Crack Tube at the crack tip. It can be seen that 16 elements surrounding the crack tips are used, and they share a node at the crack tip. For this case, the number of element rings enclosing the crack tips is 4 . In the new mesh generator, the number of element rings is set as a variable so that it is easy to refine the mesh along the crack front and check the path independence of the $J$-integral. Figure 4 indicates the dimensions of the cutting cross-section of the Crack Tube. 


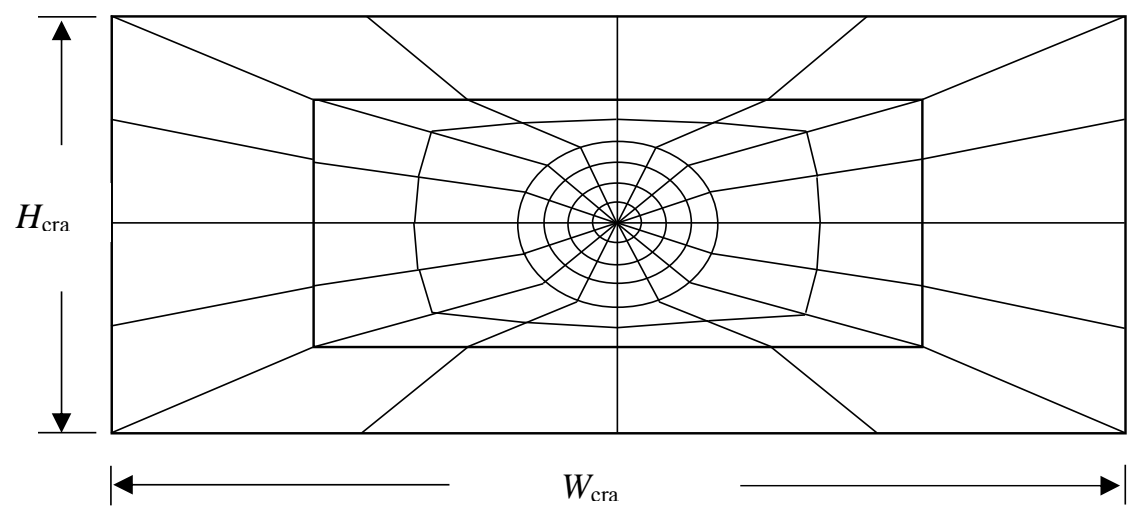

Figure 4. Mesh Design of Cutting Cross-section of Crack Tube at Crack Tip

The mesh model of the Crack Tube is created using a sweep technique. Firstly, the Crack Tube is cut into sufficient segments along the crack front and the cutting cross-sections are set perpendicular to the tangent along the crack front at the cutting points. Then, nodes are inserted on the cutting cross-sections, creating elements of the Crack Tube simultaneously. By sweeping the cutting cross-section shown in Figure 4 along the surface crack front, 3D-coordinates of nodes are determined. Finally, dimensions of certain cutting cross-sections are reduced to form transition elements (Figures 5 and 6). The mesh generation of Part A and Part B are quite straightforward and will not be discussed herein.

After the surface crack block shown in Figure 3 is generated, FE mesh model of a cracked T-butt joint can be produced by adding a vertical attachment and the fillet weld on a central cracked plain plate. Subsequently, the chord-brace intersection zone can be created using the double mapping approach shown in Figure 7. After all the mesh models of the other sub-zones are completed, they are merged with the chord-brace intersection zone to form the completed FE mesh model of a cracked CHS T/Y-joint. The detailed derivation of coordinate transformation can be found in Ref. [20]. Figure 8 shows a typical completed mesh model of such a cracked CHS T/Y-joint for $\theta=60^{\circ}$.

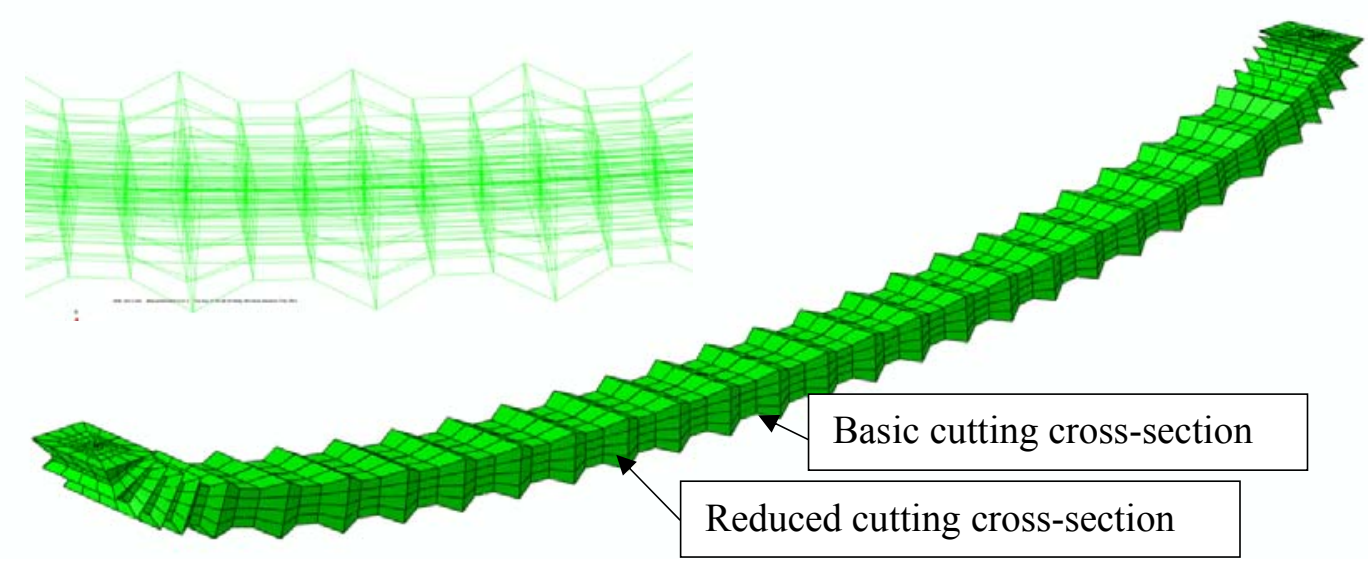

Figure 5. Mesh Design of Crack Tube Created Using a Sweep Process 


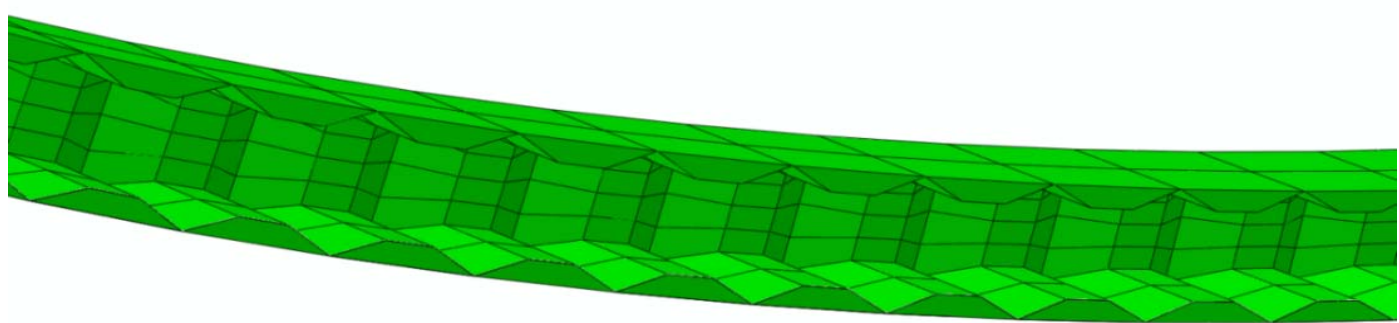

Figure 6. Transition Elements of Crack Tube Through Thickness Direction

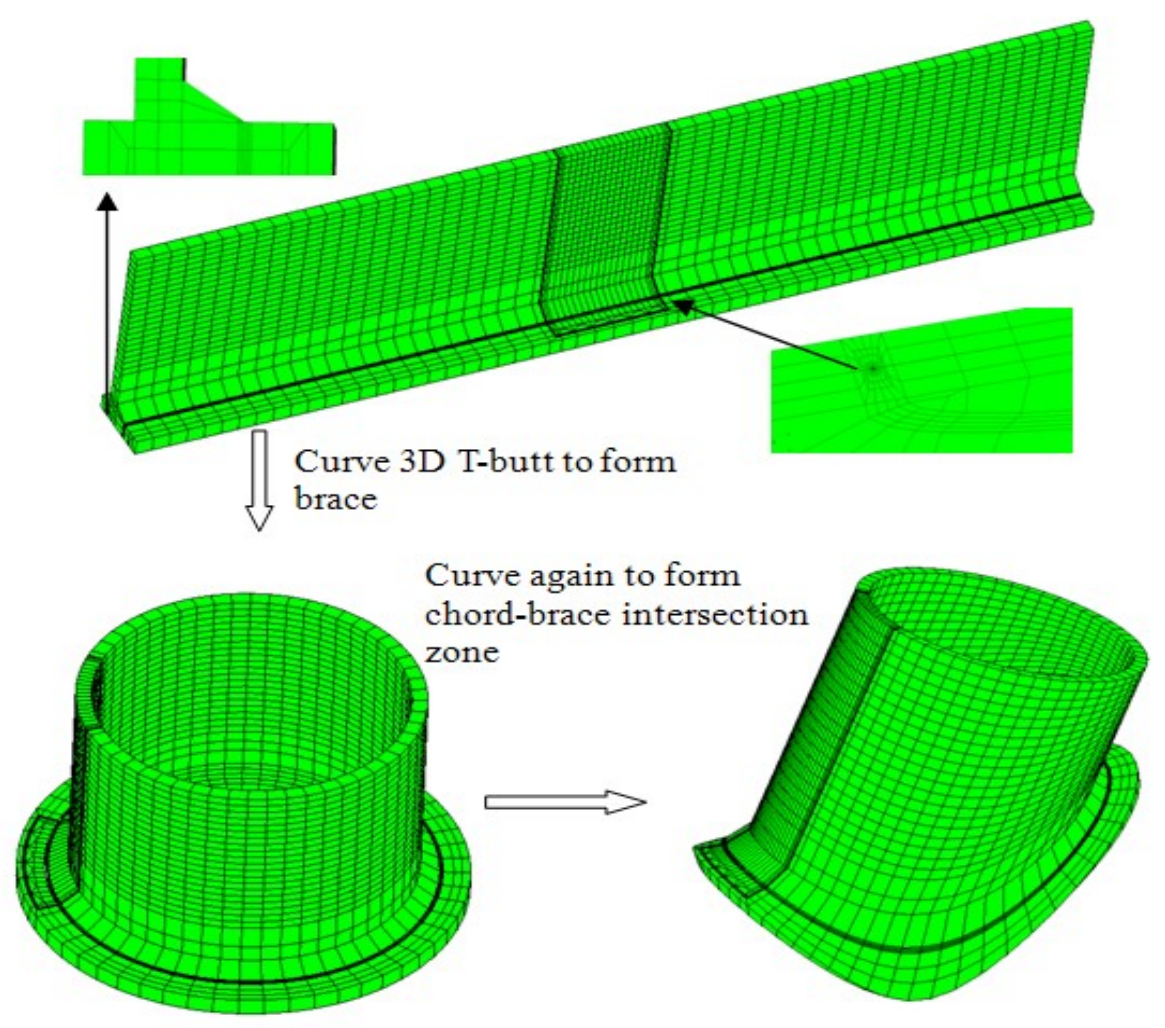

Figure 7. Double Mapping a T-butt to Form Chord-brace Intersection Zone 


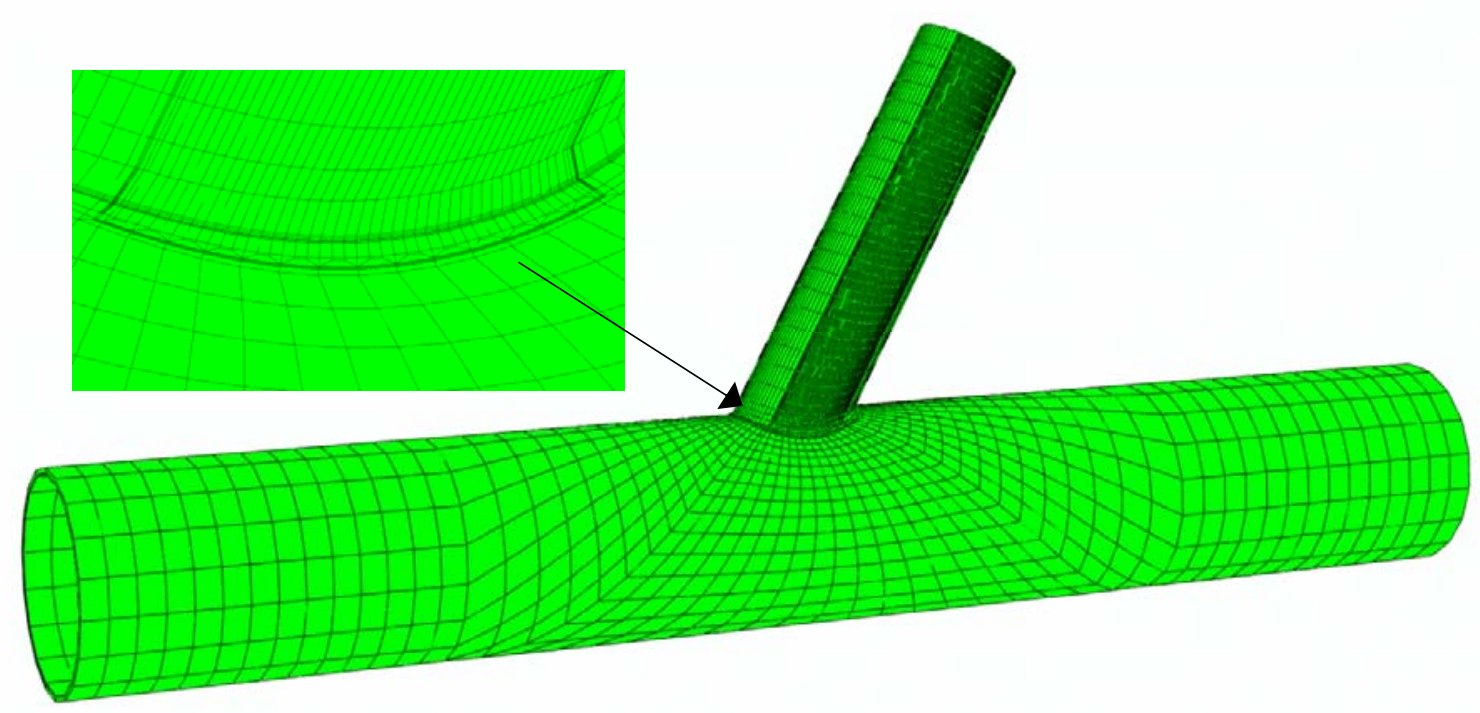

Figure 8. Completed Mesh Model of a Cracked CHS T/Y-joint $\left(\theta=60^{\circ}\right)$

\subsection{Mesh Refinement Schemes}

In order to improve the accuracy of the SIF results, two types of mesh refinement schemes are adopted in the new mesh generator. The first type is used to refine the local mesh of the Crack Tube. Element rings enclosing the crack front and the number of divisions (number of cutting cross-sections) along the crack front are set as two variables so that it is easy to refine the mesh of the Crack Tube. The second type is used to refine the global mesh of the entire chord. Number of divisions along the chord-brace intersecting curve is set as a variable. It has been validated that a minimum of 40 divisions along the chord-brace intersecting curve is sufficient to capture the stress distribution at the chord-brace intersection zone of a typical CHS joint (Chiew et al. [11], Shao and Lie [13]). In practice, the crack depth and length of a surface crack can vary widely. If the crack depth is relatively shallow such as $a / t_{0}=0.2$, the dimensions of the Crack Tube, $W_{\text {cra }}$ and $H_{\text {cra }}$ indicated in Figure 4 must be sufficiently small so as to avoid affecting the mesh of Part B of the surface crack block. For shallower surface crack, the mesh transition between the Crack Tube and Part A is critical as element size of Part A is significantly larger than elements of the Crack Tube. This may bring uncertain effect on the accuracy of the SIF results. In order to smooth the mesh transition between the Crack Tube and Part A, a novel mesh refinement scheme is designed to increase the element layers at Part A. Figure 9 shows one application of such mesh refinement scheme with 4 element layers at Part A. Simultaneously, number of element layers of the entire chord along its thickness direction is increased to 4 so that the global mesh of the chord is refined. The number of element layers at Part A is also set as a variable in the new mesh generator. 


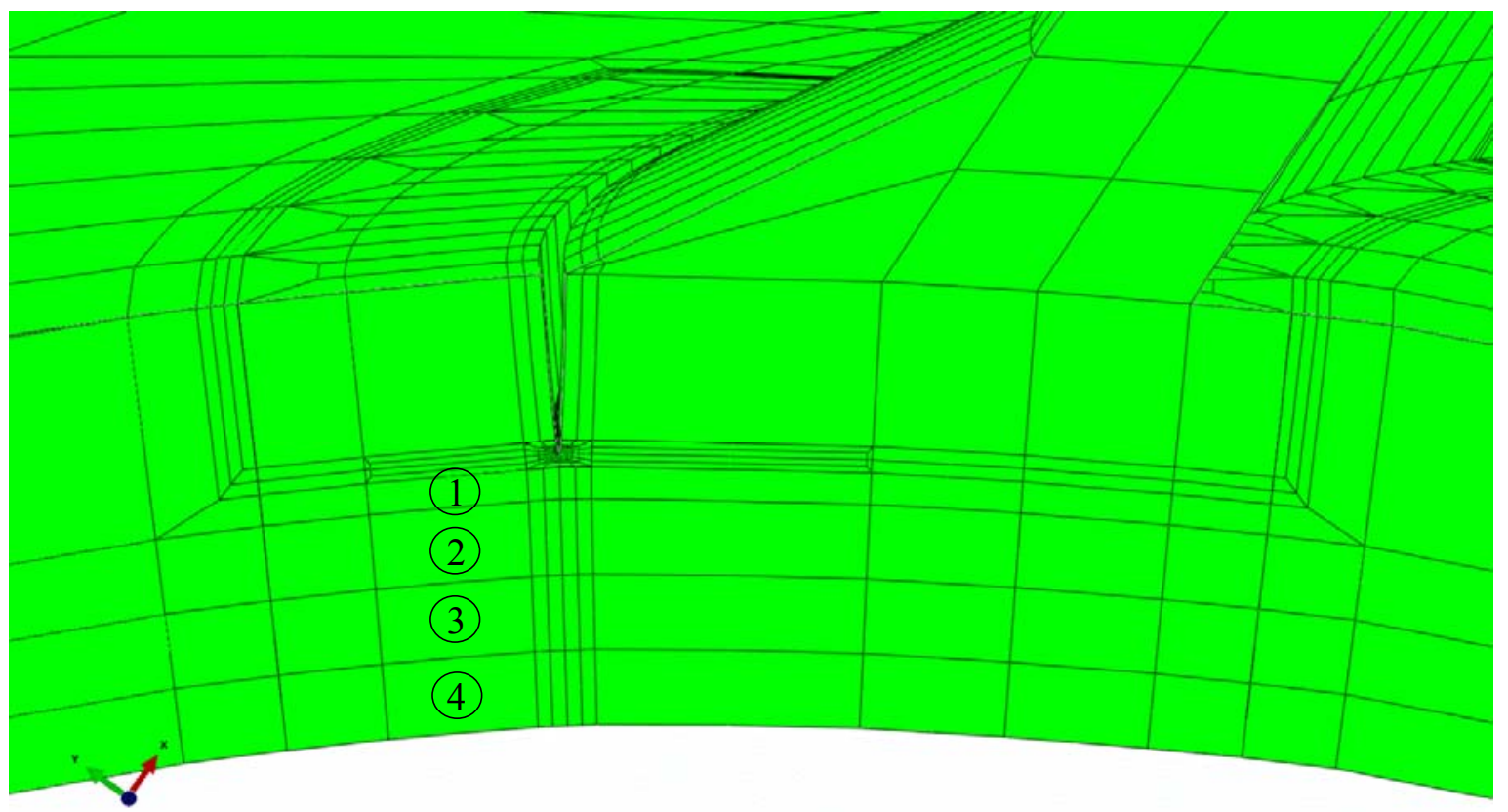

Figure 9. Mesh Refinement Scheme at Part A

\section{BOUNDARY CONDITION AND LOADING}

In this section, the boundary conditions of a cracked CHS T/Y-joint and the three types of loading applied are introduced and their magnitudes are defined accordingly.

\subsection{Boundary Conditions}

By examining previous research works (Huang and Hancock [5], Rhee [6], Bowness and Lee [7, 8], Cao et al. [9], Lie et al. [10], Chiew et al. [11]), it is found that all nodes at two ends of the chord are generally fixed in FE analysis. This type of boundary condition is reasonable as both ends of the chord are connected with adjacent members in practice. Therefore, in this study, fixed boundary conditions are used throughout in the FE analyses as shown in Figure 10.

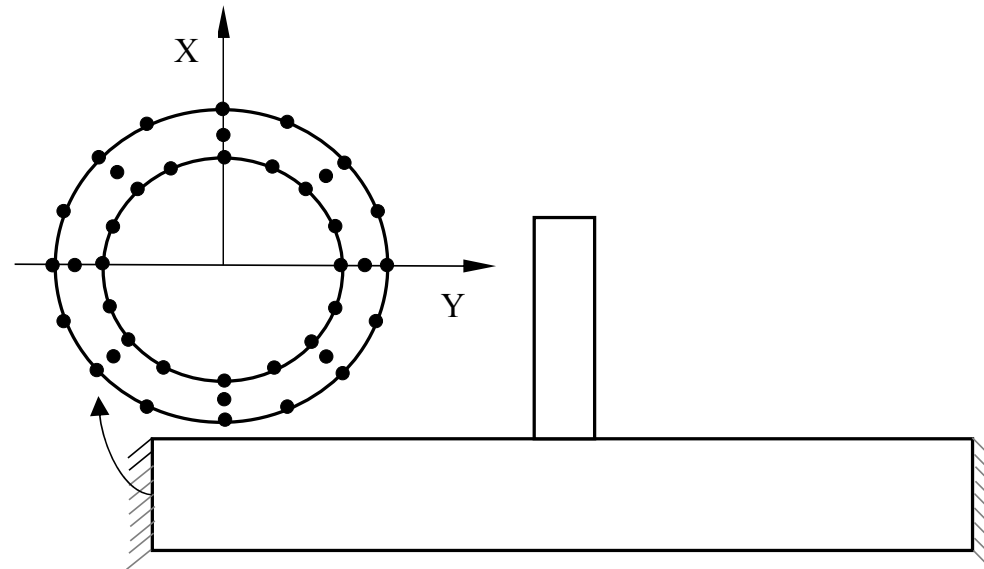

Figure 10. Boundary Conditions of Cracked CHS T/Y-joints 


\subsection{Applied Loading}

The general form of the SIF of a cracked CHS joint can be expressed as

$$
K=Y(g) \sigma_{\mathrm{n}} \sqrt{\pi a}
$$

where $Y(g)$ is the shape factor depending on the geometry of the CHS joint and the crack shape, $\sigma_{\mathrm{n}}$ is the nominal stress and $a$ is the crack depth. For CHS joints subjected to axial loading, the nominal stress is defined as

$\sigma_{\mathrm{n}}=\frac{4 P}{\left(\pi\left[d_{1}^{2}-\left(d_{1}-2 t_{1}\right)^{2}\right]\right)}$

For CHS joints subjected to in-plane bending, the nominal stress is defined as

$$
\sigma_{\mathrm{n}}=\frac{32 d_{1} M_{\mathrm{i}}}{\left(\pi\left[d_{1}^{4}-\left(d_{1}-2 t_{1}\right)^{4}\right]\right)}
$$

For CHS joints subjected to out-of-plane bending, the nominal stress is defined as

$$
\sigma_{\mathrm{n}}=\frac{32 d_{1} M_{\mathrm{o}}}{\left(\pi\left[d_{1}^{4}-\left(d_{1}-2 t_{1}\right)^{4}\right]\right)}
$$

In this study, the nominal stress is fixed as $1 \mathrm{MPa}$ for all the cracked CHS T/Y-joints. The magnitudes of the axial loading, $P$, in-plane bending, $M_{\mathrm{i}}$ and out-of-plane bending, $M_{\mathrm{o}}$ can be derived using Eqs. 2-4, respectively.

\section{CALIBRATION OF FE MESH MODELS}

The accuracy and convergence of the generated FE mesh models are verified in this section. Firstly, the SIFs of four cracked nozzles are compared with results from mesh models generated using a well-known commercial software called FEACrack ${ }^{\mathrm{TM}}$ [21]. After that, mesh convergence test is carried out. Finally, SIFs of five cracked CHS T-joints are compared with the experimental and numerical results reported by other researchers.

\subsection{Comparison with FEACrack ${ }^{\mathrm{TM}}$ Mesh Model}

There are very few published SIF data of cracked CHS T/Y-joints available in the literature. Most of them were published many years ago, and they were based on coarse mesh models at that time. In this sub-section, SIFs of 4 cracked nozzles generated by the new mesh generator are compared with results from FE mesh models produced by FEACrack ${ }^{\mathrm{TM}}$ [21] software. The dimensions of 4 cracked nozzles are listed in Table 2 . The geometry of the nozzle is very close to the CHS T/Y-joint where the inner part of the chord at the chord-brace zone is removed. Figures 11(a), (b) and (c) compare the details of the FE mesh models generated by the new mesh generator and FEACrack ${ }^{\mathrm{TM}}$ [21] software. It can be seen that the mesh at the crack tip is three times more refined for mesh model generated by FEACrack ${ }^{\mathrm{TM}}$ [21] software, and 8 element rings are used at the crack front. For 
mesh models generated by FEACrack ${ }^{\mathrm{TM}}$ [21] software, there are a total of 64160 elements and 332150 nodes; whereas for the mesh models generated by the new mesh generator, there are only 26102 elements and 119452 nodes.

Table 2. Dimensions and Surface Crack Sizes of Cracked Nozzles

\begin{tabular}{ccccccc}
\hline \multirow{2}{*}{ Dimensions } & $d_{0}(\mathrm{~mm})$ & $d_{1}(\mathrm{~mm})$ & $t_{0}(\mathrm{~mm})$ & $t_{1}(\mathrm{~mm})$ & $l_{0}(\mathrm{~mm})$ & $l_{1}(\mathrm{~mm})$ \\
\cline { 2 - 7 } & 360 & 108 & 10 & 10 & 2520 & 800 \\
\hline Surface crack & $1 \mathrm{st}$ & $2 \mathrm{nd}$ & $3 \mathrm{rd}$ & 4 th & - & - \\
\hline$a(\mathrm{~mm})$ & 2 & 4 & 6 & 8 & - & - \\
$2 c(\mathrm{~mm})$ & 32 & 64 & 128 & 256 & - & - \\
\hline
\end{tabular}

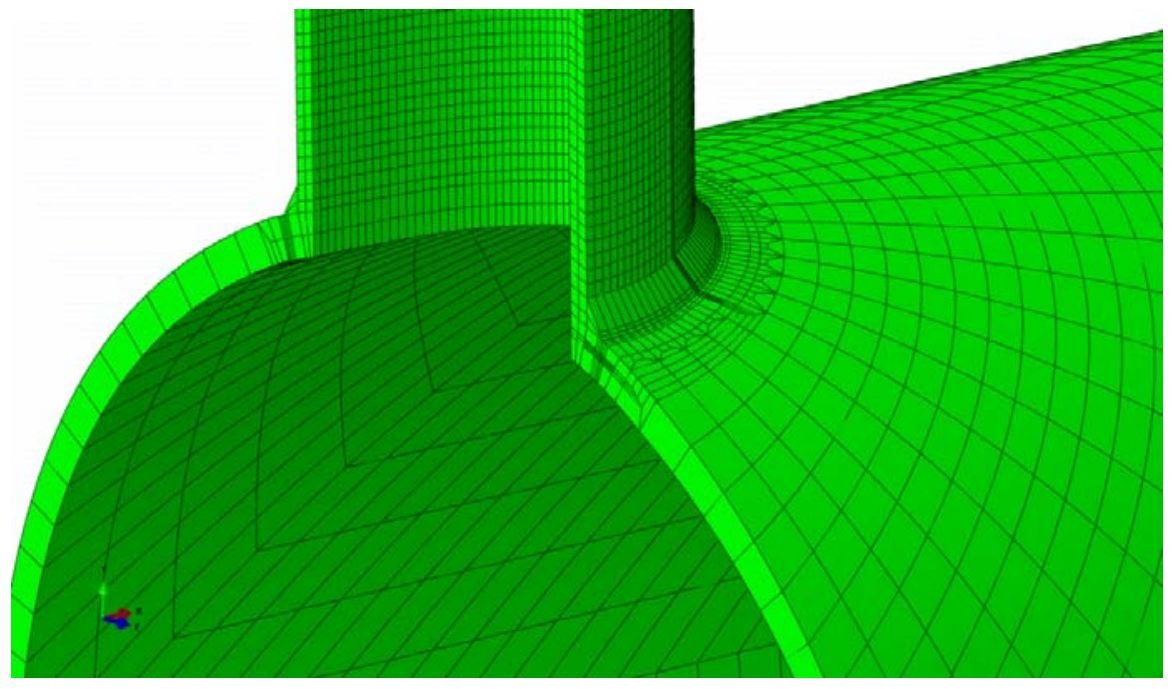

(a) A Half Mesh Model of a Cracked Nozzle Generated by FEACrack ${ }^{\mathrm{TM}}$ [21]

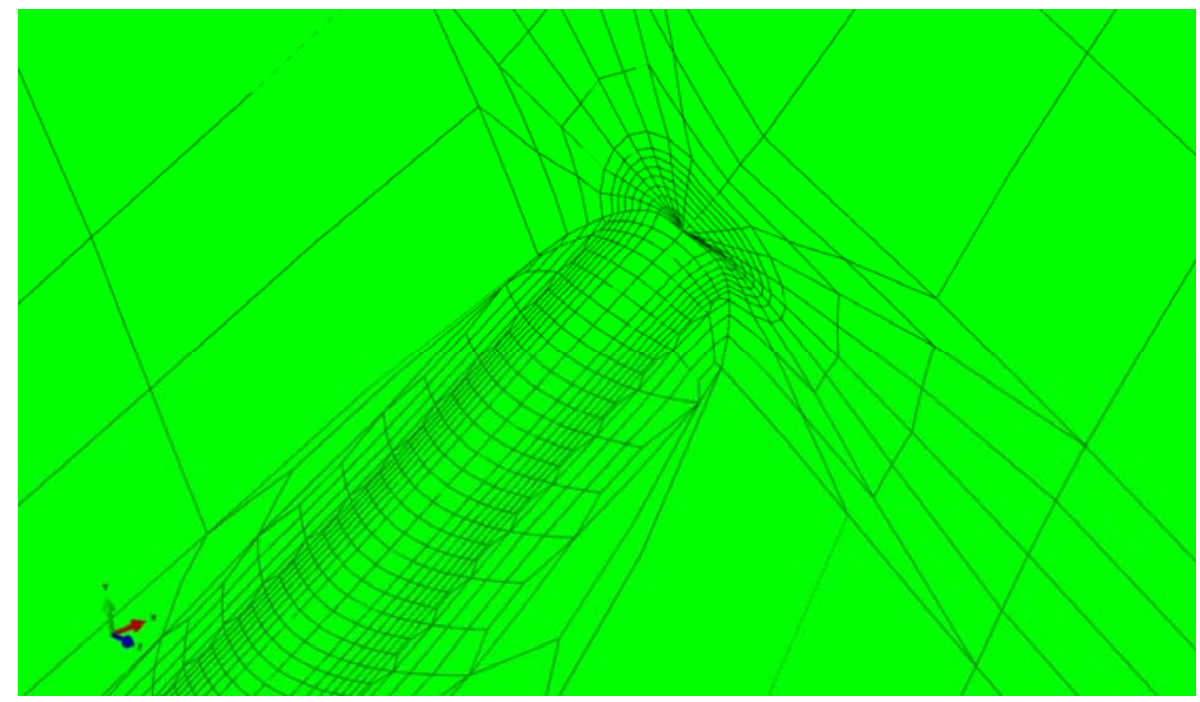

(b) Mesh Details at Crack Tips of mesh Models Generated by FEACrack ${ }^{\mathrm{TM}}$ [21] 


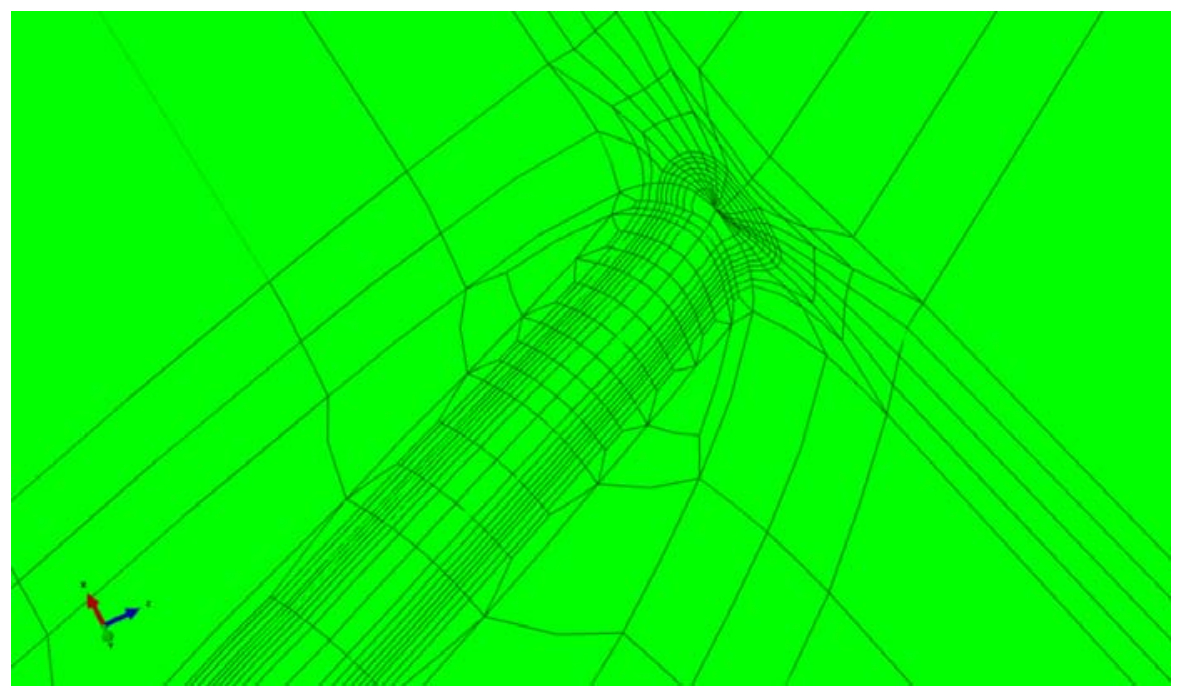

(c) Mesh Details at the Crack Tips of Mesh Models Generated by New Mesh Generator

Figure 11. Comparison of FE Mesh Models of a Cracked Nozzle Generated by FEACrack ${ }^{\mathrm{TM}}$ [21] Software and New Mesh Generator

Figures 12 compares the shape factors at the deepest point and crack ends of the four cracked nozzles subjected to axial loading and out-of-plane bending. In Figure 12, D and E denote the shape factors at the deepest point and crack ends, respectively. It can be seen that shape factors obtained from FE mesh models generated by the new mesh generator agree well with results obtained from those created by FEACrack ${ }^{\mathrm{TM}}$ [21] software. However, it is important to recognize that it does not guarantee the accuracy of the SIFs for shallower surface crack as the effect of element layers at Part A has not been investigated.

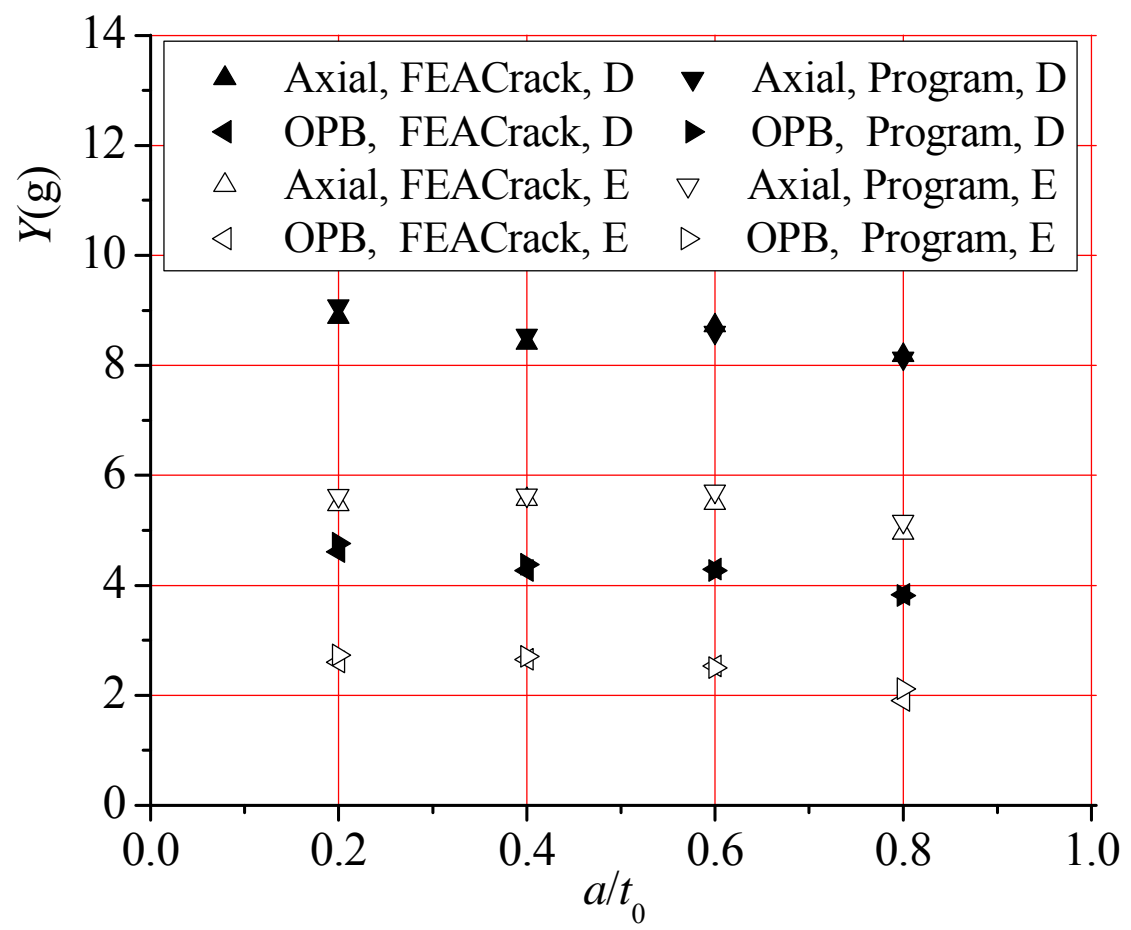

Figure 12. Comparison of Shape Factors $Y(g)$ of Cracked Nozzles 


\subsection{Mesh Convergence Test}

In this sub-section, mesh convergence test of the FE mesh models is carried out on two aspects, which are the effect of element layers of Part A in the surface crack block and element rings enclosing the crack front. Figures 13(a) and (b) show the effect of element layers of Part A on the distribution of shape factors along the entire crack front. It is found that for cracked CHS T/Y-joints with $a / t_{0} \leq 0.5$, at least 2 element layers must be designed for Part A. For cracked CHS T/Y-joints with $0.5<a / t_{0} \leq 0.8,1$ element layer designed for Part A is sufficient to produce accurate SIFs. The definition of $\phi$ is illustrated in Figure 14. In this study, 3 element layers for Part A are adopted as an optimum choice for cracked CHS T/Y-joints with $a / t_{0} \leq 0.5$.

Figure 15 show the effect of element rings enclosing the crack front on the distribution of the shape factors along the entire crack front. It can be seen that 3 element rings are sufficient to produce accurate shape factors at the crack tips further away from the crack ends. However, as mentioned in Refs. [21, 22], SIFs produced from the first element ring are generally not accurate and should be discarded. All SIF values are derived from the $J$-integral in ABAQUS [22] software. In order to check the path independence of the $J$-integral, 4 element rings enclosing the crack front are adopted in this study.

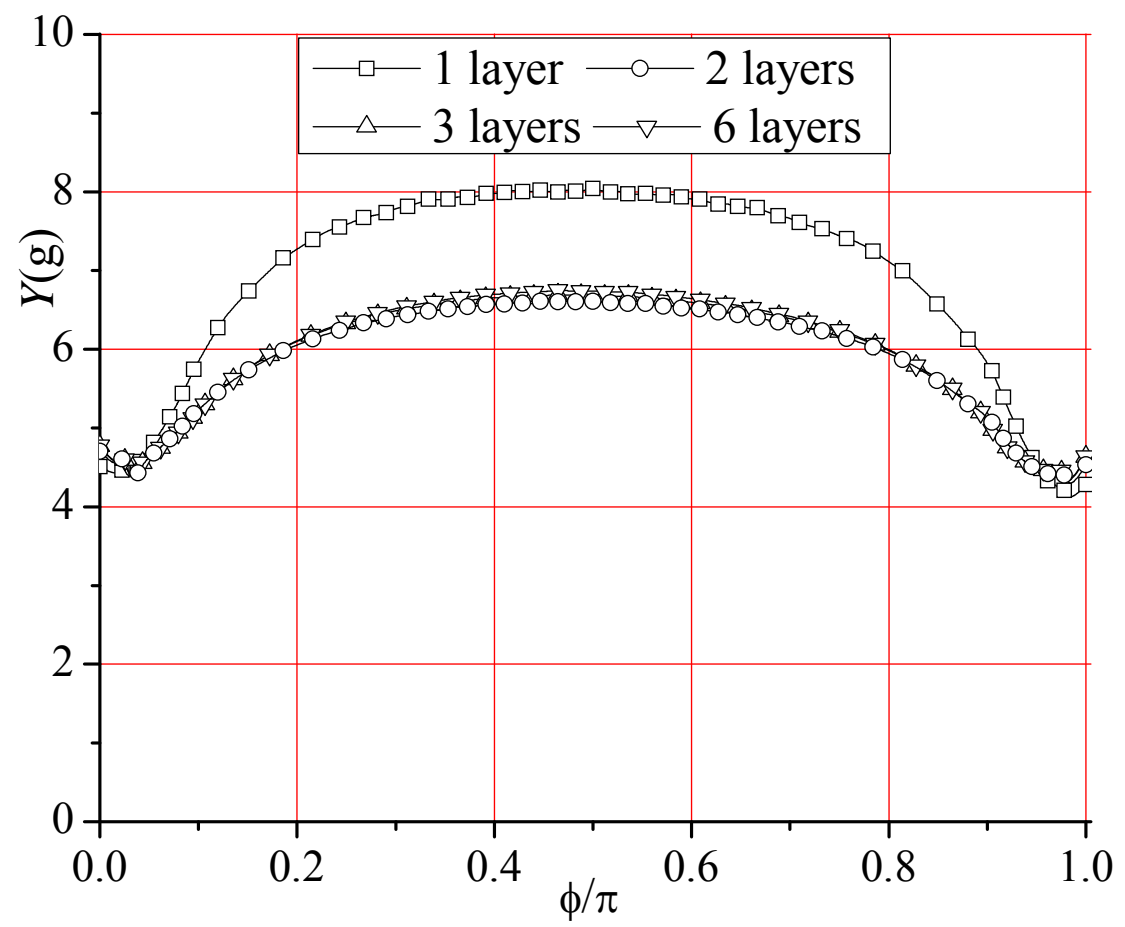

(a) $\alpha=14, \beta=0.5, \gamma=18, \tau=0.6, \theta=60^{\circ}, a / t_{0}=0.2, c / a=8$, Axial Loading 


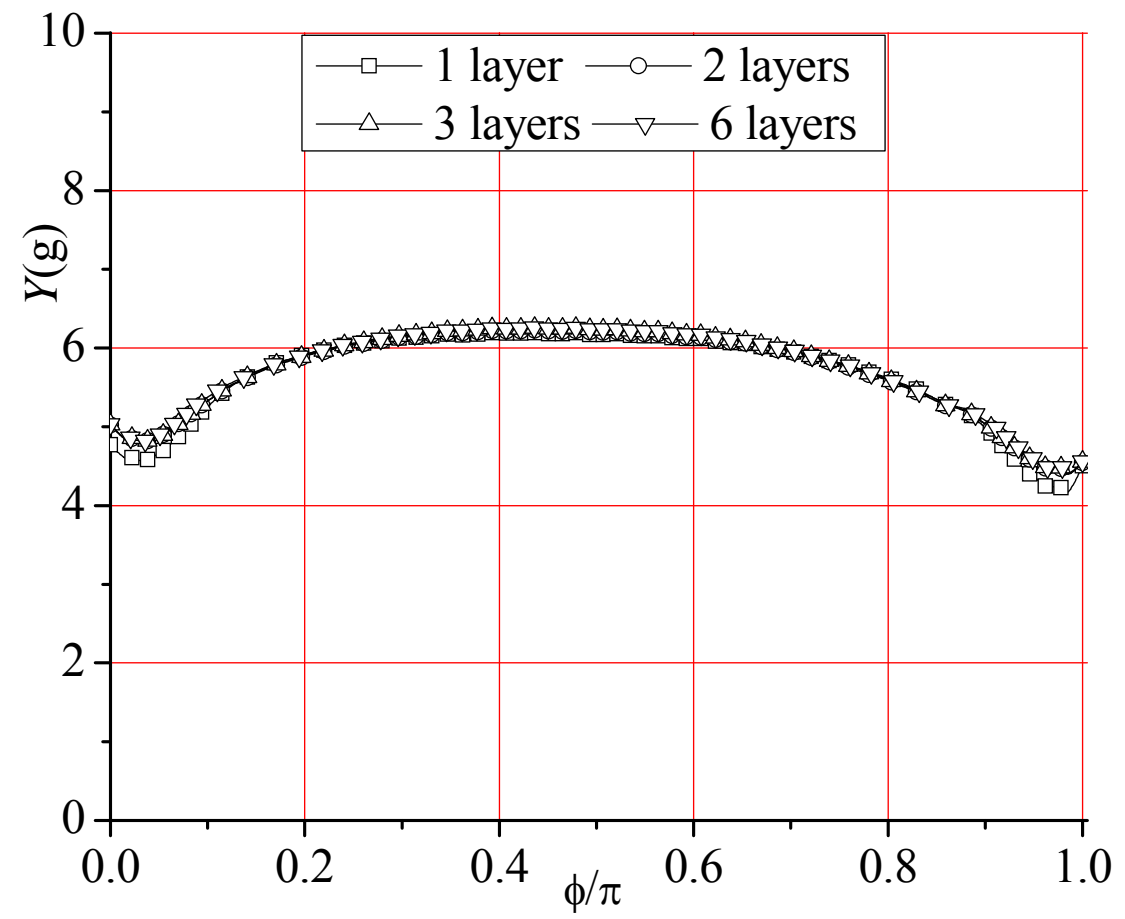

(b) $\alpha=14, \beta=0.5, \gamma=18, \tau=0.6, \theta=60^{\circ}, a / t_{0}=0.5, c / a=8$, Axial Loading Figure 13. Effect of Element Layers at Part A of Surface Crack Block

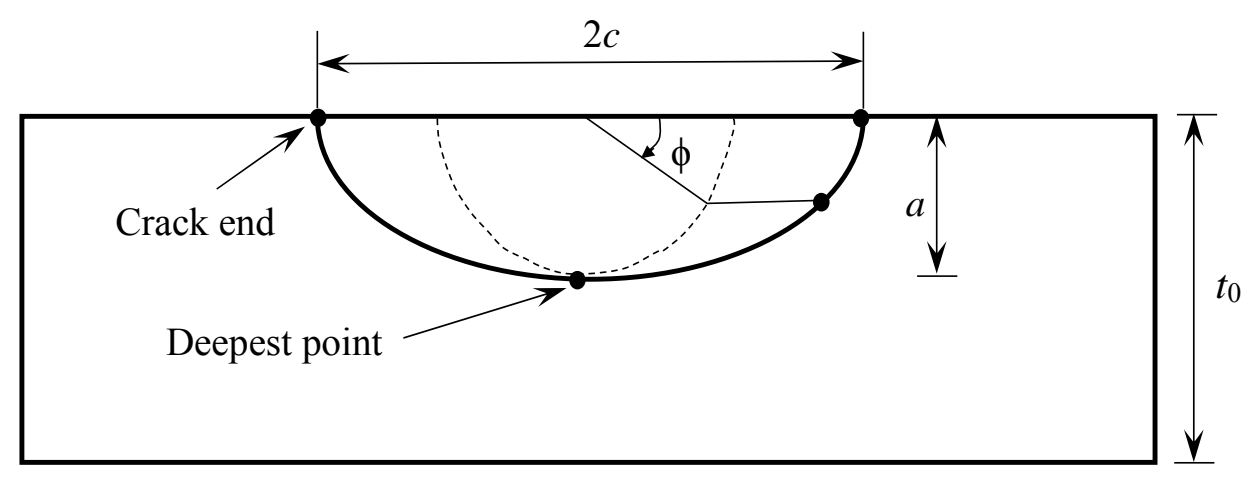

Figure 14. Definition of Crack Front Angle $\phi$ 


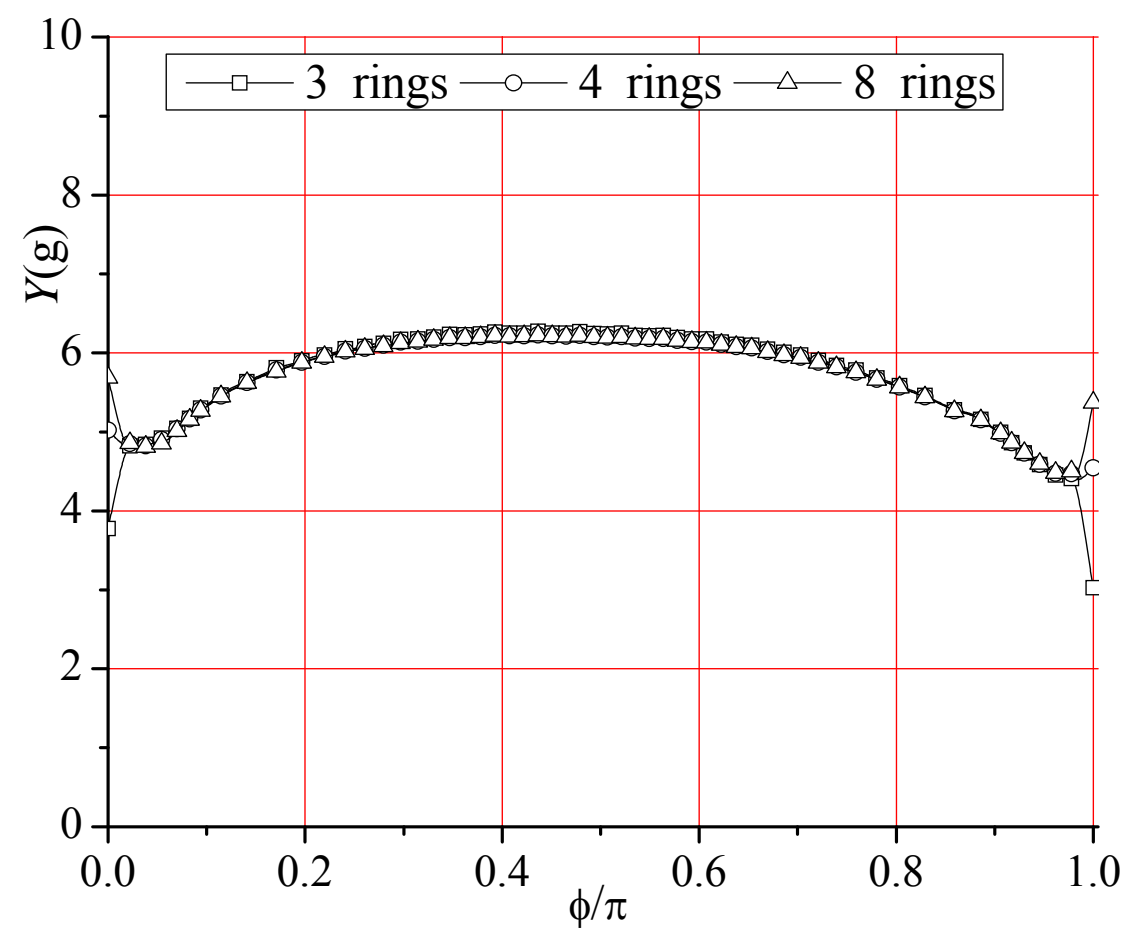

Figure 15. Effect of Element Rings Enclosing Crack Front on $Y(g)$ $\left(\alpha=14, \beta=0.5, \gamma=18, \tau=0.6, \theta=60^{\circ}, a / t_{0}=0.5, c / a=8\right.$, Axial Loading)

\subsection{SIFs Derived from Experimental Results}

The SIFs data reported by Ritchie and Hujskens [23] is widely used by researchers to validate their own FE models of cracked CHS T/Y-joints. Ritchie and Hujskens [23] carried out fatigue test on a CHS T-joint subjected to axial loading and estimated the SIFs at the deepest point located at the saddle. Table 3 lists the dimensions of the cracked CHS T-joints and the crack shapes used for calibration purposes. Figure 16 shows the comparison of the shape factors obtained in this study and results reported by other researchers (Bowness and Lee [7, 8], Ritchie and Huijskens [23], Shen and Choo [24]). It can be seen that the differences among these curves remain rather large. The difference may be caused by two facts. Firstly, the SIFs estimated from experimental test shown in Figure 16 are the average value of 5 curves reported in Ref. [23]. In fact, Ritchie and Hujskens [23] only estimated the range of the SIFs at the deepest points of 5 cracked CHS T-joints rather than provided actual SIF results. Therefore, the difference between the SIFs obtained in this study and the average SIFs shown in Figure 16 is quite acceptable as the average SIF curve does not represent the accurate one. Secondly, the FE mesh models generated by Bowness and Lee [7-8] are very coarse at that time. Therefore, their mesh models may not be dense enough to produce accurate SIF values. It can be seen that shape factors obtained by Shen and Choo [24] agree quiet well with the results obtained in this study. This is expected because FE mesh models generated by Shen and Choo [24] are created based on the cracked nozzle of FEACrack ${ }^{\mathrm{TM}}$ [19] software where the mesh quality of their mesh models is very high. 
Table 3. Dimensions and Surface Crack Sizes of Cracked CHS T/Y-joints

\begin{tabular}{ccccccc}
\hline \multirow{2}{*}{ Dimensions } & $d_{0}(\mathrm{~mm})$ & $d_{1}(\mathrm{~mm})$ & $t_{0}(\mathrm{~mm})$ & $t_{1}(\mathrm{~mm})$ & $l_{0}(\mathrm{~mm})$ & $l_{1}(\mathrm{~mm})$ \\
\cline { 2 - 7 } & 914 & 457 & 32 & 16 & 3900 & 1250 \\
\hline Surface crack & $1^{\text {st }}$ & $2^{\text {nd }}$ & $3^{\text {rd }}$ & $4^{\text {th }}$ & $5^{\text {th }}$ & - \\
\hline$a(\mathrm{~mm})$ & 6.5 & 11.2 & 14.3 & 18.0 & 24.2 & - \\
$2 c(\mathrm{~mm})$ & 30.2 & 60.9 & 91.0 & 123.3 & 202.2 & - \\
\hline
\end{tabular}

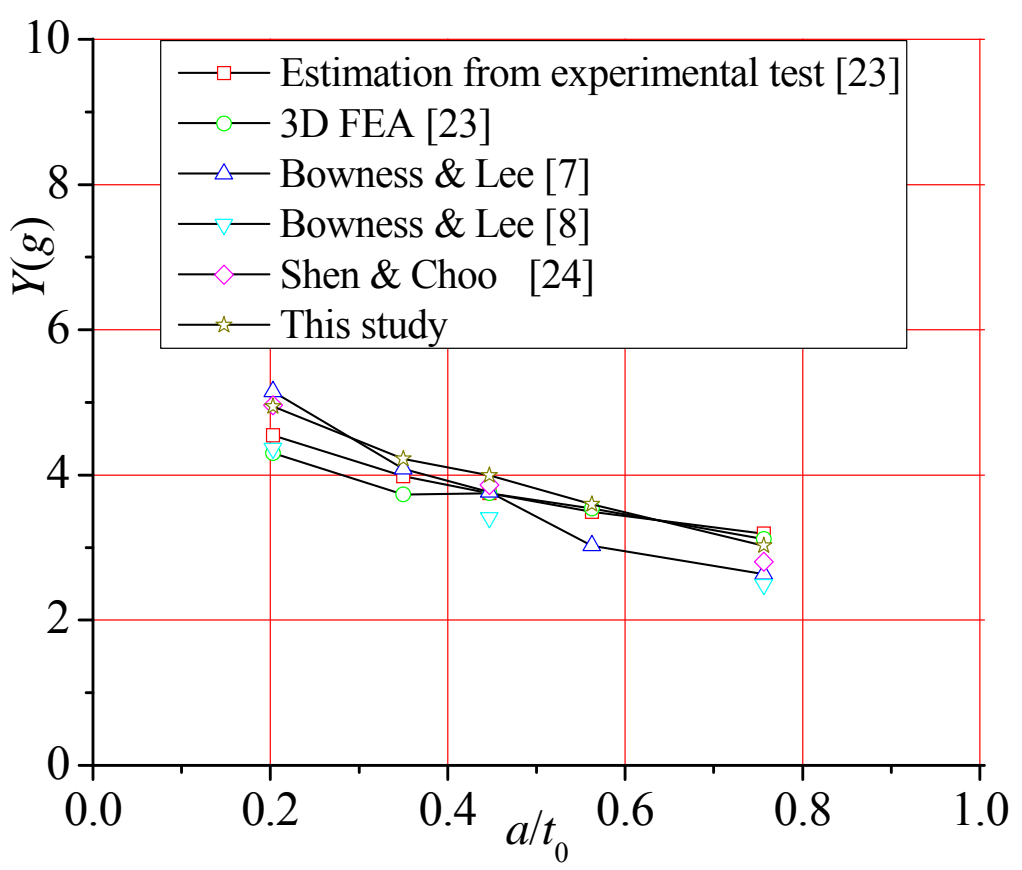

Figure 16. Comparison of the Shape Factors at Deepest Point

\section{STRESS INTENSITY FACTORS OF CHS T/Y-JOINTS}

A total of 246 cracked CHS T/Y-joints subjected to axial loading, in-plane bending and out-of-plane bending are analyzed, and the corresponding SIFs are calculated along the crack front. The objective of carrying such analyses is to investigate the effects of $\beta, \gamma, \tau, \theta, a / t_{0}$ and $c / a$ parameters on the SIFs. Although the surface crack present in CHS T/Y-joints is a mixed mode one, $K_{\mathrm{I}}$ is still the dominant one as values of $K_{\text {II }}$ and $K_{\text {III }}$ are much smaller as compared to $K_{\mathrm{I}}$ [6-8]. Therefore, only $K_{\mathrm{I}}$ values are converted to shape factor $Y(g)$ and presented in this section.

\subsection{Effect of Geometrical Parameters}

Figures 17(a) and (b) show the effect of $\beta$ on $Y(g)$. It can be seen that $Y(g)$ increases as $\beta$ increases from 0.3 to 0.5 . Thereafter, $Y(g)$ decreases when $\beta$ is further increased to 0.8 . This indicates a non-linear relationship between $\beta$ and $Y(g)$. Figures 18(a) and (b) show the effect of $\gamma$ on $Y(g)$ values. It can be seen that the relationship between $Y(g)$ and $\gamma$ is directly proportional. Figures 19(a) and (b) show the effect of $\tau$ on $Y(g)$ values. The relationship between $Y(g)$ and $\tau$ is also almost linear. Figure 20 shows the effect of $\theta$ on $Y(g)$ values of cracked CHS T/Y-joints subjected to axial loading. As the angle $\theta$ increases from $30^{\circ}$ to $90^{\circ}, Y(\mathrm{~g})$ increases gradually, and the maximum value $Y(g)$ occurs in the CHS T-joint rather than at Y-joint under the same loading condition. For a particular parameter, only one type of loading case is presented. However, similar trend is also observed for the other two loading cases. 
It is found that the geometrical parameters $\beta, \gamma, \tau, \theta$ have the same effect on the hot spot stress of CHS T/Y-joints. For instance, the hot spot stress of CHS T/Y-joints subjected to axial loading increases as $\beta$ increases from 0.3 to 0.5 . Thereafter, the hot spot stress decreases when $\beta$ is further increased to 0.8 . It shows that SIFs of cracked CHS T/Y-joints are significantly influenced by the severity of the stress concentration at the chord-brace intersection region.

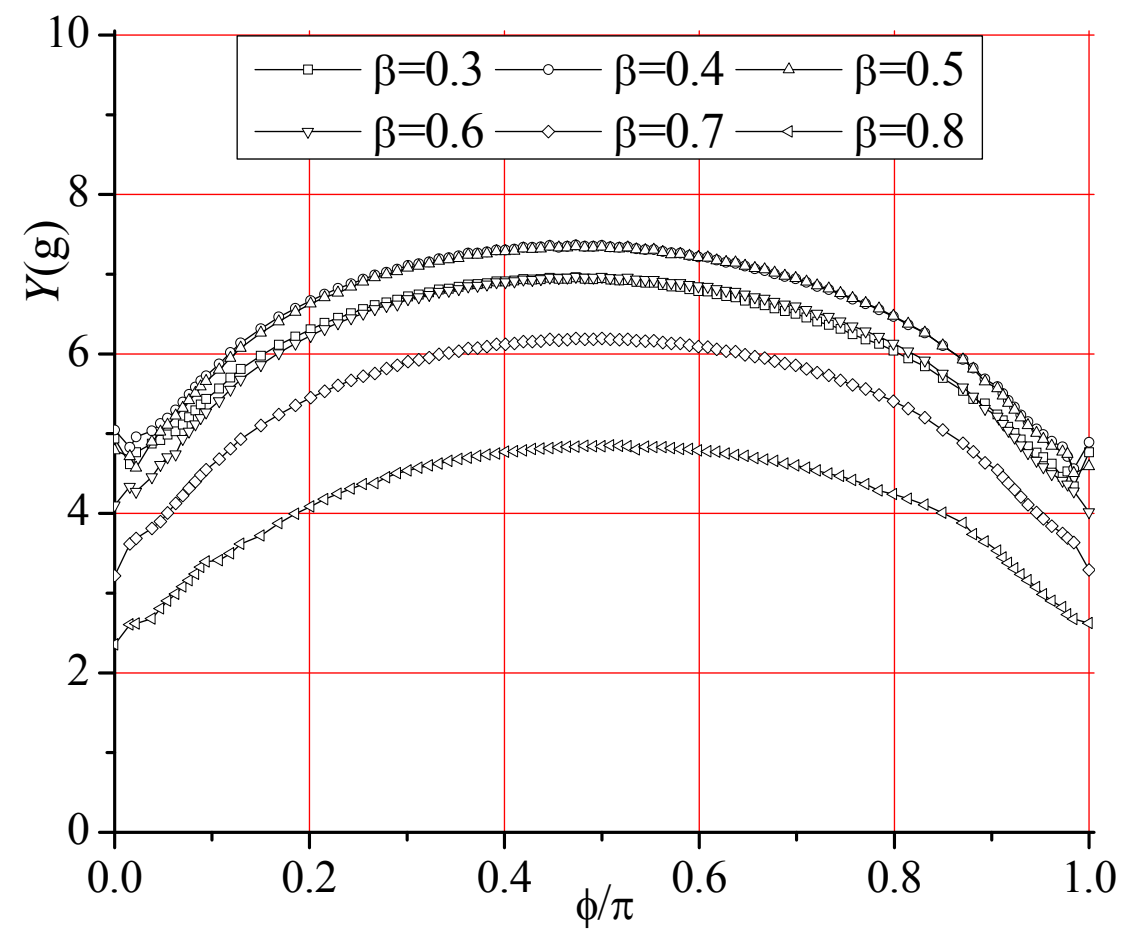

(a) $\alpha=14, \gamma=18, \tau=0.6, \theta=60^{\circ}, a / t_{0}=0.2, c / a=8$, Axial Loading

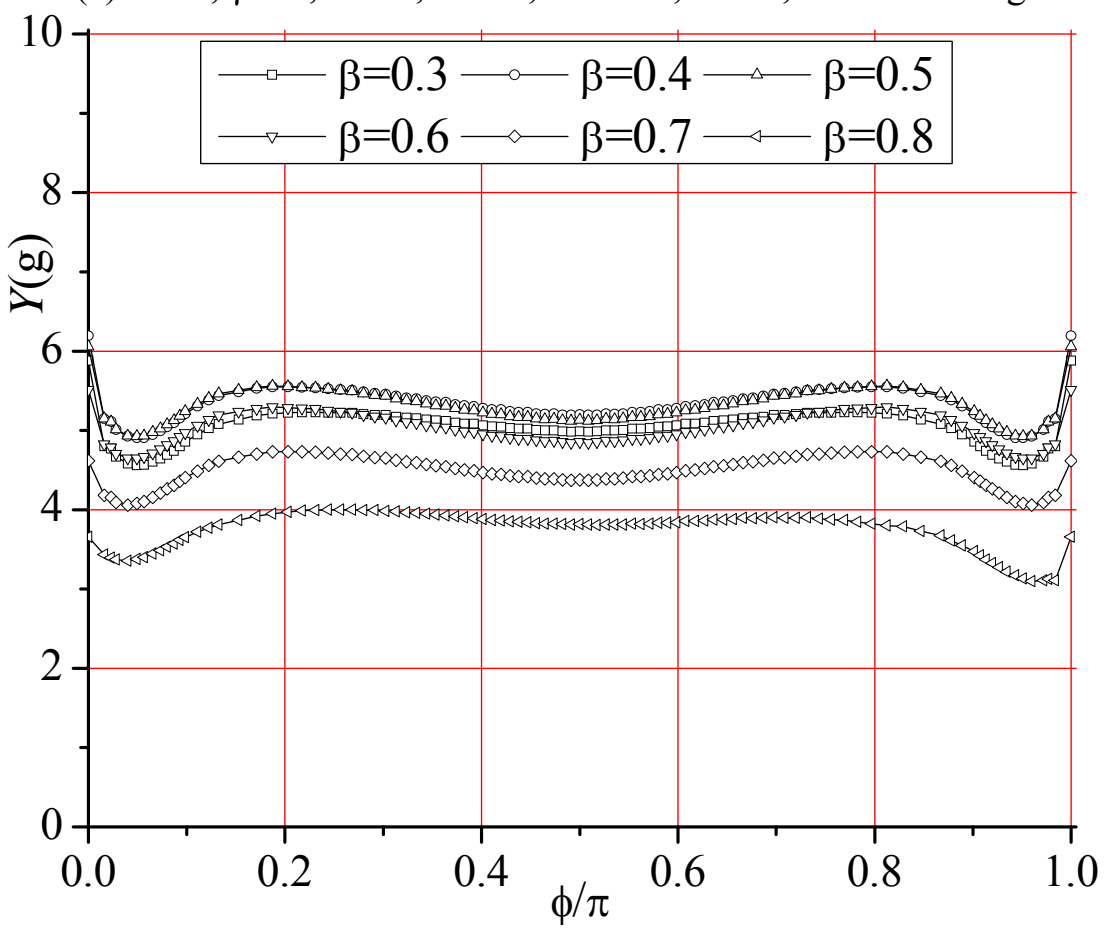

(b) $\alpha=14, \gamma=18, \tau=0.6, \theta=60^{\circ}, a / t_{0}=0.6, c / a=6$, Axial Loading

Figure 17. Effect of $\beta$ on $K_{\mathrm{I}}$ of Cracked CHS T/Y-joints 


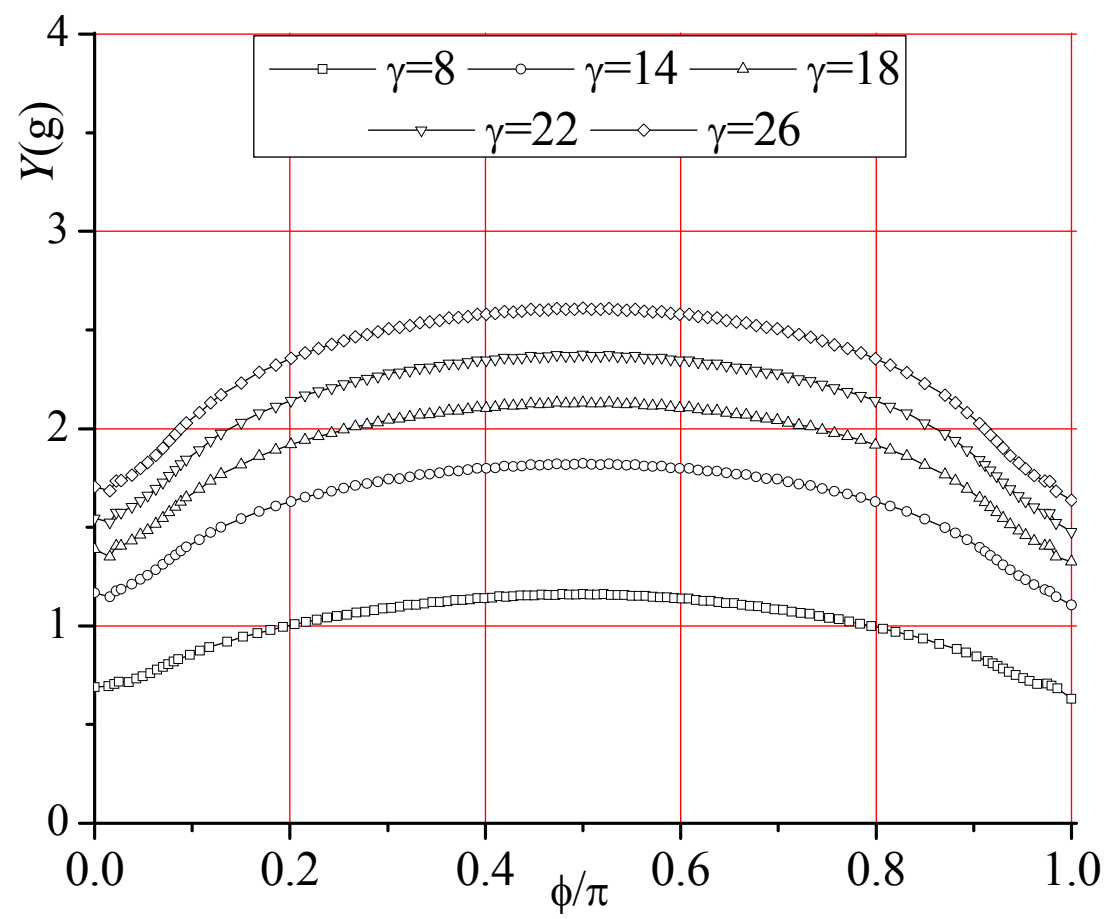

(a) $\alpha=14, \beta=0.5, \tau=0.6, \theta=60^{\circ}, a / t_{0}=0.2, c / a=8$, In-plane Bending

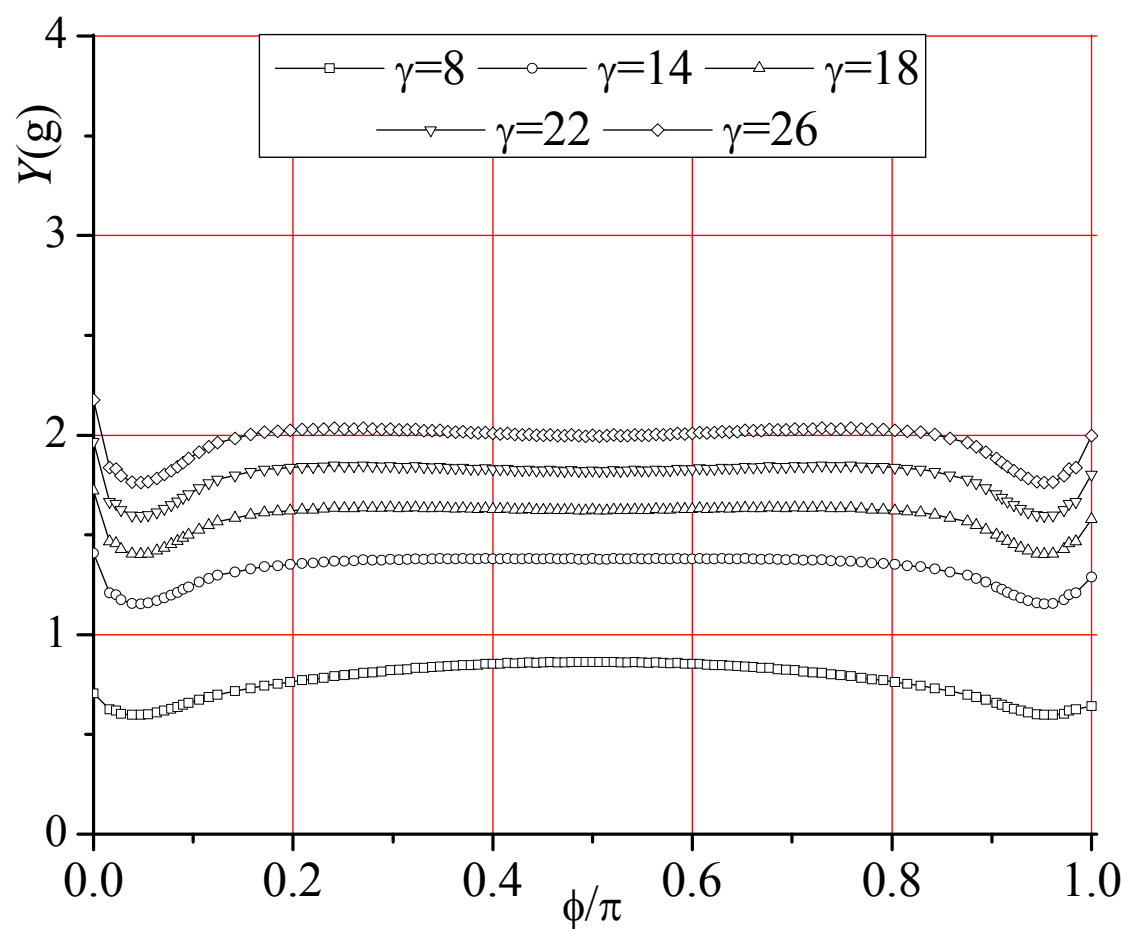

(b) $\alpha=14, \beta=0.5, \tau=0.6, \theta=60^{\circ}, a / t_{0}=0.6, c / a=6$, In-plane Bending

Figure 18. Effect of $\gamma$ on $K_{\mathrm{I}}$ of Cracked CHS T/Y-joints 


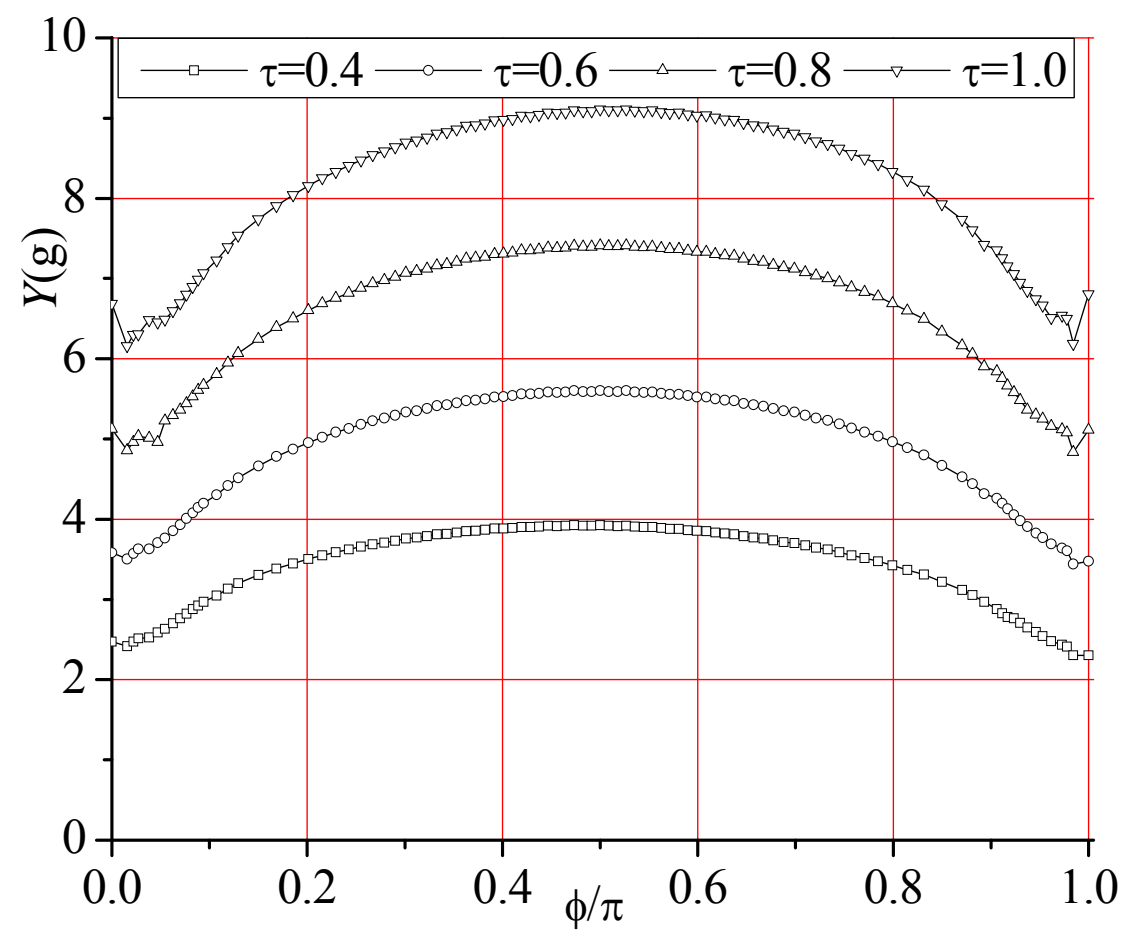

(a) $\alpha=14, \beta=0.5, \gamma=18, \theta=60^{\circ}, a / t_{0}=0.2, c / a=10$, Out-of-plane Bending

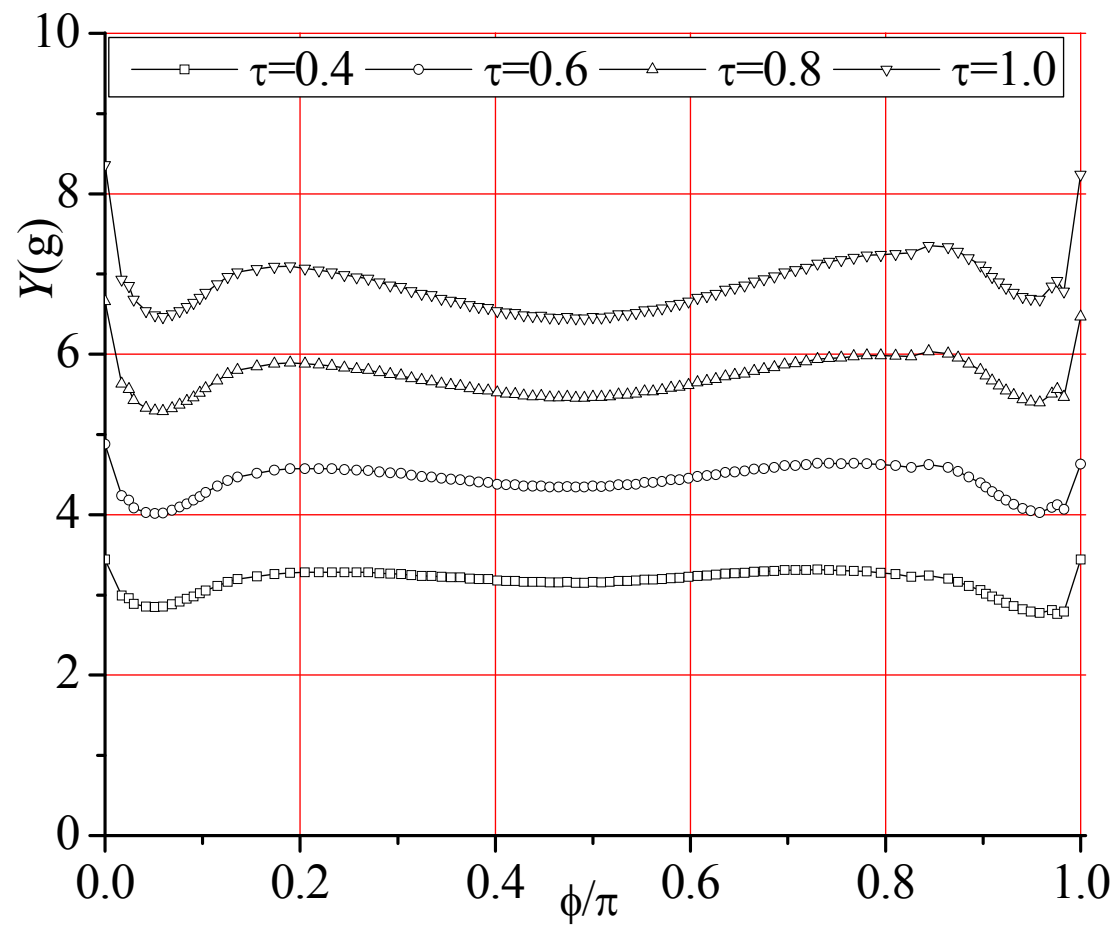

(b) $\alpha=14, \beta=0.5, \gamma=18, \theta=60^{\circ}, a / t_{0}=0.6, c / a=6$, Out-of-plane Bending

Figure 19. Effect of $\tau$ on $K_{\mathrm{I}}$ of Cracked CHS T/Y-joints 


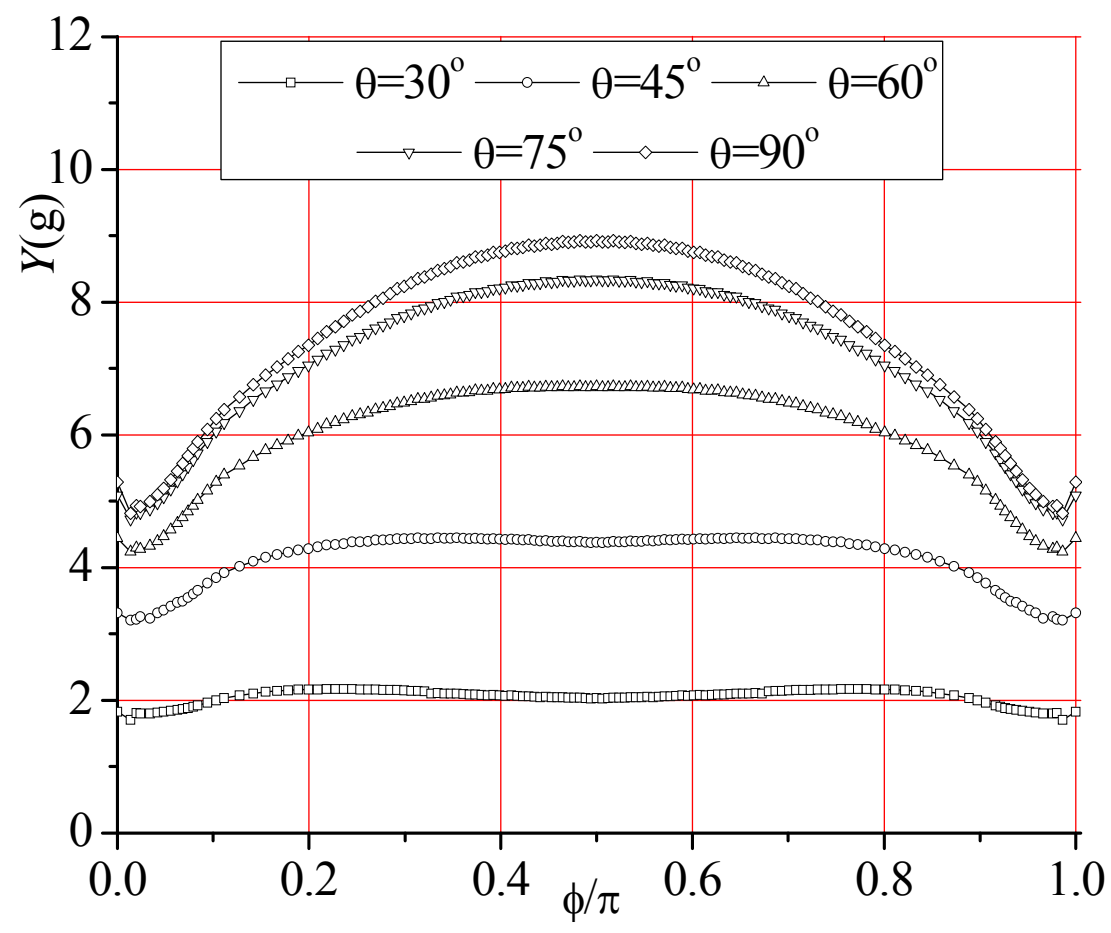

Figure 20. Effect of $\theta$ on $K_{\mathrm{I}}$ of Cracked CHS T/Y-joints subjected to Axial Loading $\left(\alpha=14, \beta=0.5, \gamma=18, \tau=0.6, a / t_{0}=0.6, c / a=10\right)$

\subsection{Effect of Crack Shapes}

Figures 21(a) and (b) show the effect of crack depth $a / t_{0}$ on $Y(g)$ values for CHS T/Y-joints subjected to axial loading. It can be seen that the distributions of $Y(g)$ values are completely different for a crack located at the saddle or at the crown. When the crack is located at the saddle, $Y(g)$ at the deepest point increases gradually as the crack depth increases, and after the maximum value is reached, it decreases even if the crack depth increases further. For a cracked CHS T/Y-joint with a crack located at the crown, the distributions of $Y(g)$ values increase as the crack depth increases at the deepest point. A similar finding is observed for cracked CHS T/Y-joints subjected to in-plane bending and out-of-plane bending cases.

Figure 22 shows the effect of the crack length $c / a$ on $Y(g)$ values for CHS T/Y-joints subjected to axial loading. It can be seen that the distributions of $Y(g)$ values are the same for a crack located at the saddle or at the crown. The peak value of $Y(g)$ along the surface crack front tends to shift from the crack ends to the deepest point as the crack length increases. This is particularly true for a CHS $\mathrm{T} / \mathrm{Y}$-joint containing a surface crack located at the saddle. Moreover, there exists a non-linear relationship between $Y(g)$ and $c / a$. A similar finding is observed for cracked CHS T/Y-joints subjected to in-plane bending and out-of-plane bending cases. 


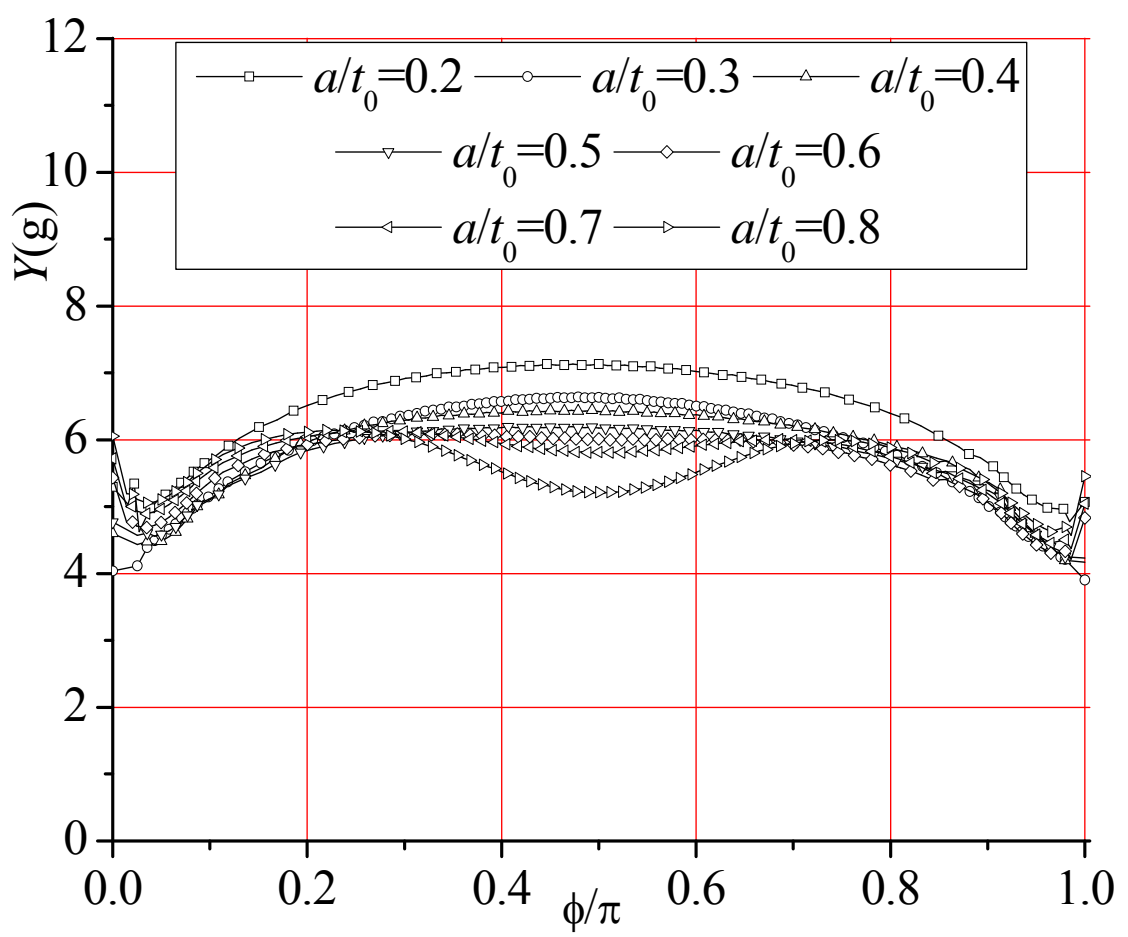

(a) $\alpha=14, \beta=0.5, \gamma=18, \tau=0.6, \theta=60^{\circ}, c / a=8$, Crack at the Saddle

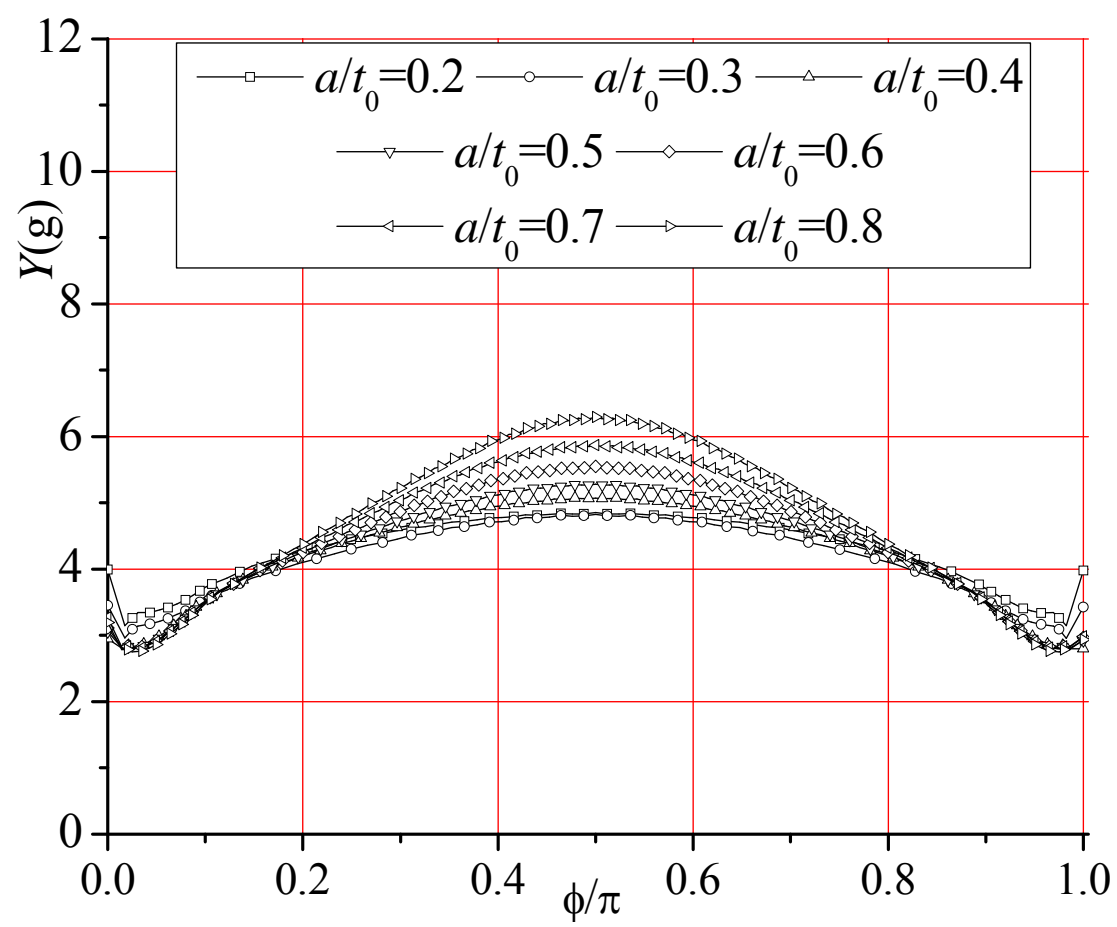

(b) $\alpha=14, \beta=0.5, \gamma=8, \tau=0.6, \theta=60^{\circ}, c / a=8$, Crack at the Crown

Figure 21. Effect of $a / t_{0}$ on $K_{\mathrm{I}}$ of Cracked CHS T/Y-joints Subjected to Axial Loading 


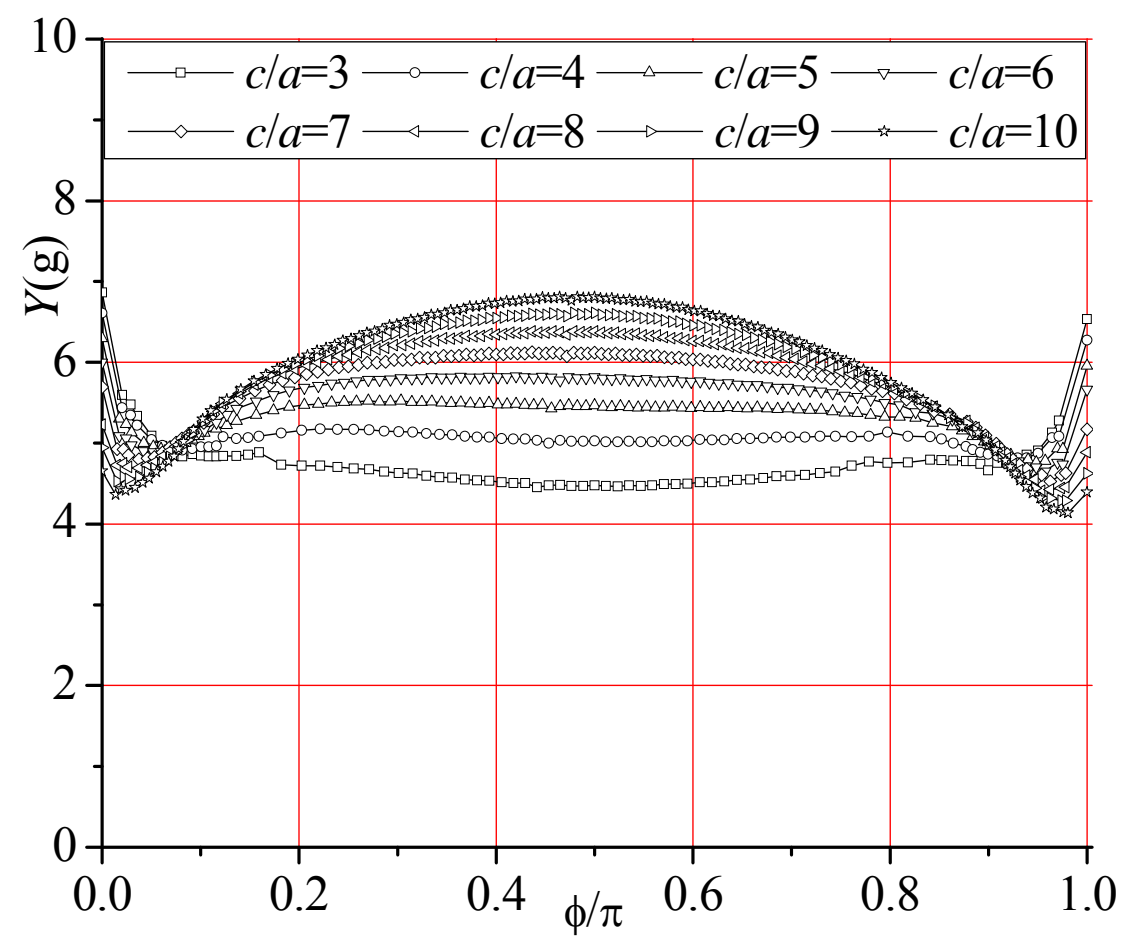

Figure 22. Effect of $c / a$ on $K_{\mathrm{I}}$ of Cracked CHS T/Y-joints Subjected to Axial Loading $\left(\alpha=14, \beta=0.5, \gamma=18, \tau=0.6, \theta=60^{\circ}, a / t_{0}=0.4\right)$

\section{ESTIMATION OF SIFS USING BS7910 (2005) INDIRECT METHOD}

The indirect method used to estimate the SIF of a cracked CHS T/Y-join is expressed as

$$
K \approx\left(M_{\mathrm{km}} M_{\mathrm{m}} \mathrm{SCF} \times(1-\mathrm{DOB})+M_{\mathrm{kb}} M_{\mathrm{b}} \mathrm{SCF} \times \mathrm{DOB}\right) \sigma_{\mathrm{n}} \sqrt{\pi a}
$$

where $a$ is the crack depth, $M_{\mathrm{km}}$ and $M_{\mathrm{kb}}$ are the weld toe magnification factors, and $M_{\mathrm{m}}$ and $M_{\mathrm{b}}$ are the plain plate shape factors. The subscripts $m$ and $b$ denote membrane and bending load respectively. SCF is the stress concentration factor and DOB is the degree of bending at the would-be location of the crack. $\sigma_{\mathrm{n}}$ is the nominal stress in the reference brace of the joint. As DOB, SCF and $\sigma_{\mathrm{n}}$ are all obtained from uncracked CHS joints, and $M_{\mathrm{kj}}, M_{\mathrm{j}}(\mathrm{j}=\mathrm{m}, \mathrm{b})$ can be calculated from parametric equations, it is clear that Eq. 5 is a very convenient approach for estimating the SIFs of any cracked CHS joint because it avoids the complexity of generating the mesh models of the surface crack.

In this section, the degree of bending (DOB) [25] recommended in BS7910 [14] is adopted, whereas SCF equations for CHS T/Y-joints subjected to three basic loading incorporated in API-RP-2A [19] are used. Equations of $M_{\mathrm{kj}}$ and $M_{\mathrm{j}}(\mathrm{j}=\mathrm{m}, \mathrm{b})$ can be found in BS7910 [14]. Figures 23 to 25 show the differences of shape factors at the deepest point for all the loading cases. The percentage differences are found ranging from $-36.9 \%$ to $77.6 \%$ for axial loading; $13.1 \%$ to $68.9 \%$ for in-plane bending; and $-32.9 \%$ to $37.9 \%$ for out-of-plane bending cases. It can be seen that the indirect method underestimates the SIFs of a crack located at the crown and at the saddle for the axial loading and out-of-plane bending, respectively. Hence, Eq. 5 should be used with caution. 


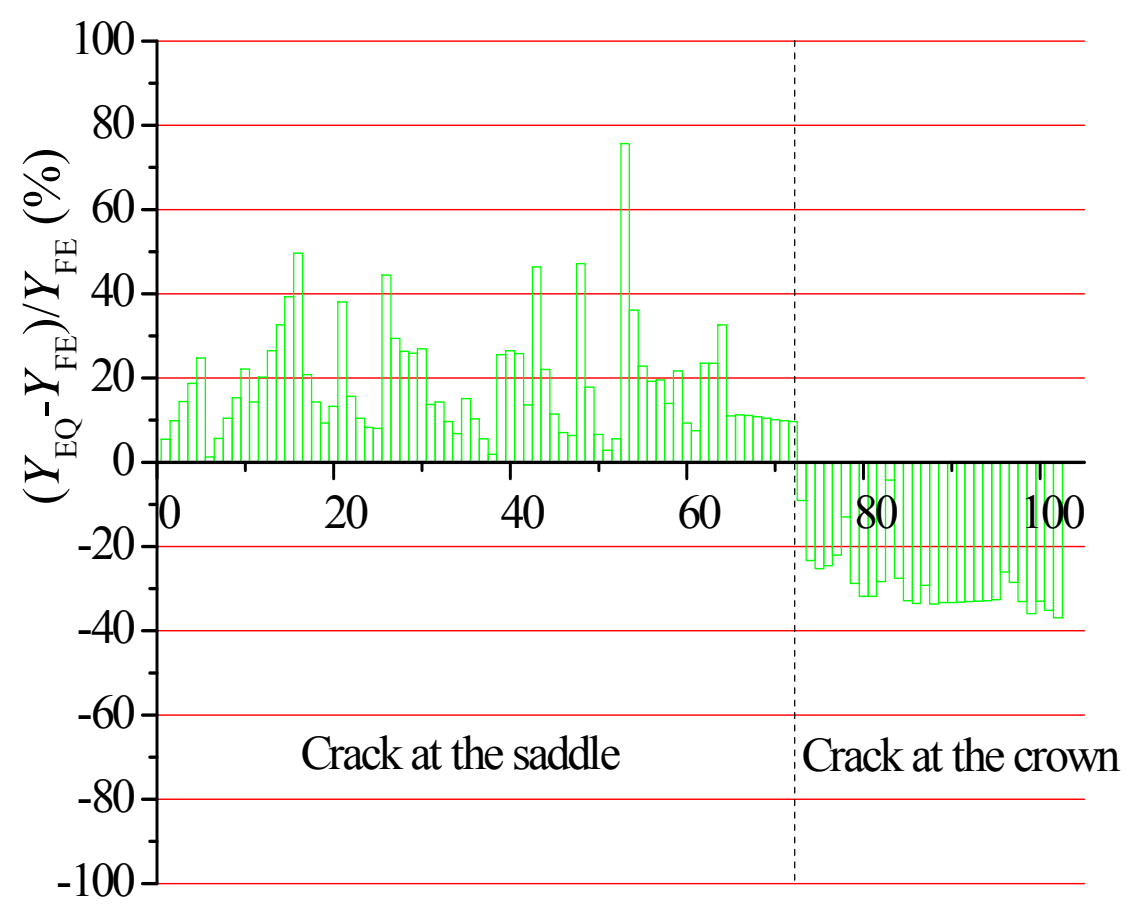

Figure 23. Comparison of Shape Factors of Cracked CHS T/Y-joints Subjected to Axial Loading

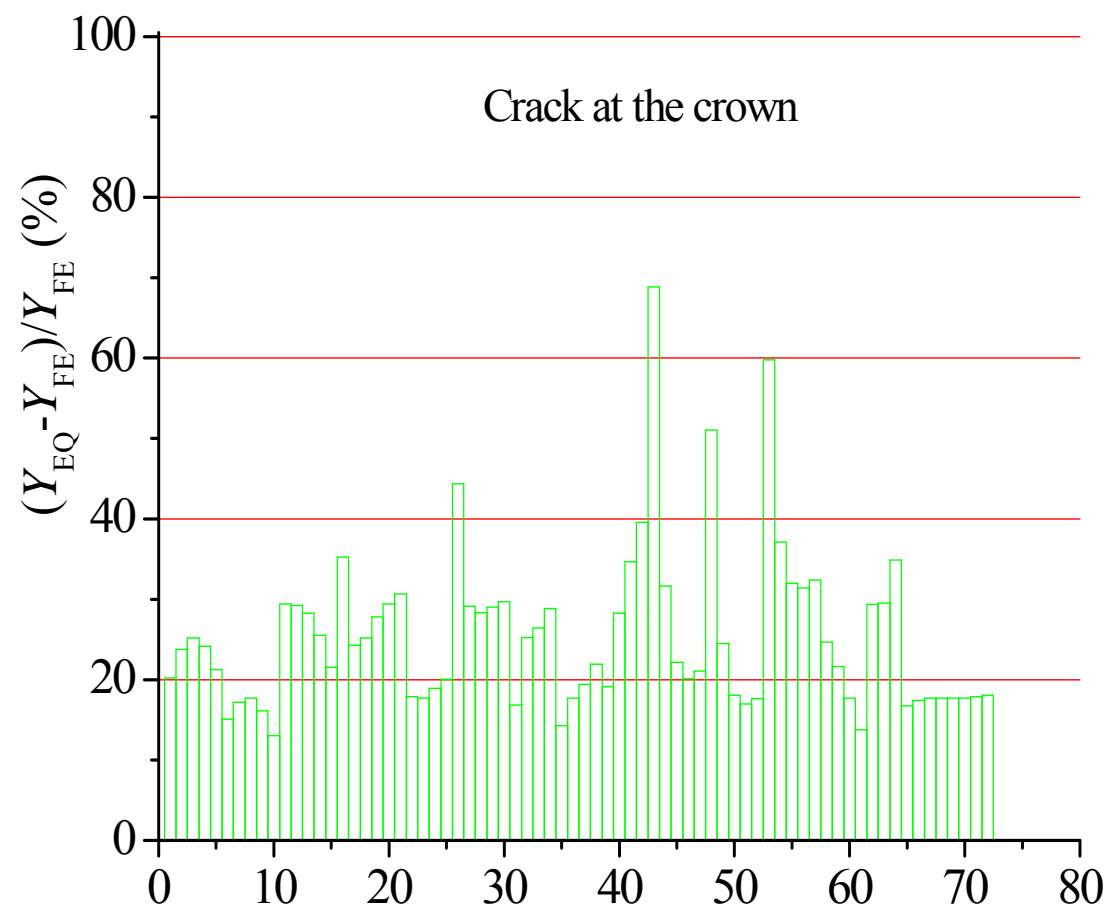

Figure 24. Comparison of Shape Factors of Cracked CHS T/Y-joints Subjected to In-plane Bending 


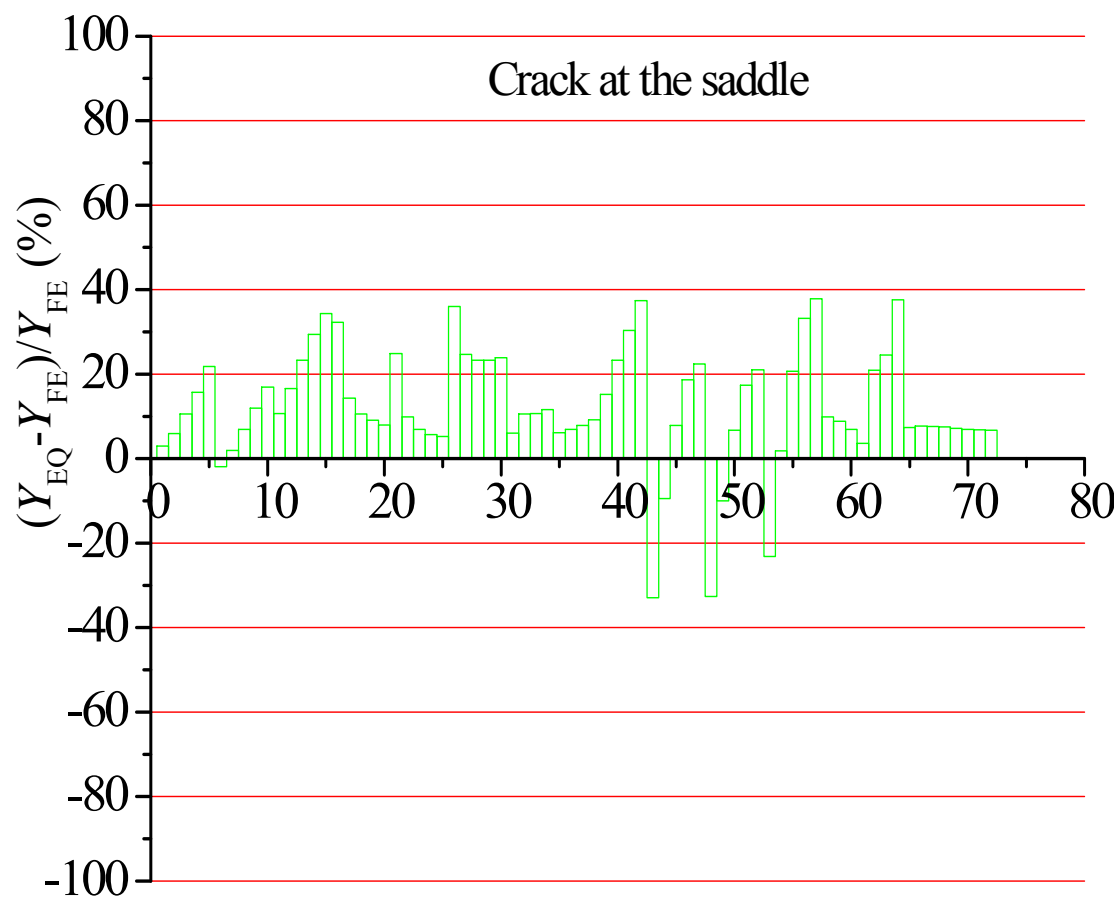

Figure 25. Comparison of Shape Factors of Cracked CHS T/Y-joints Subjected to Out-of-plane Bending

\section{CONCLUSIONS}

In this study, a new mesh generator is developed to produce high quality FE mesh models of cracked CHS T/Y-joints containing a surface crack. Extensive tests are carried out to calibrate the accuracy and convergence of the designed FE mesh models. It is found that number of element rings enclosing the crack front has a minor impact on the SIFs at crack tips further away from two crack ends. In order to check the path independence of $J$-integral, 4 element rings enclosing the crack front is found to be an optimum choice. For cracked CHS T/Y-joints containing shallow surface crack, element size in the remaining part ahead of the Crack Tube has a significant effect on SIFs and it should be sufficiently fine. A novel mesh refinement scheme is developed to increase element layers in the region ahead of the Crack Tube so as to optimize the transition mesh in this region. It is found that 3 element layers in the remaining part ahead of the Crack Tube are sufficient to produce accurate SIFs for the cracked CHS T/Y-joints.

The new mesh generator is then used to calculate the SIFs of 246 cracked CHS T/Y-joints subjected to axial loading, in-plane bending and out-of-plane bending. The SIFs at the deepest points are also estimated using the indirect method incorporated in BS7910 [14]. It is found that it does not always produce conservative results. For the axial loading, the percentage difference of the SIFs ranges from $1.3 \%$ to $77.6 \%$ for crack located at the saddle; and $-27.5 \%$ to $-36.9 \%$ for crack located at the crown. Therefore, the indirect method has consistently underestimated the SIFs when the crack is located at the crown location. This may due to the fact that parameters used in the indirect method such as the SCF and the DOB obtained are based on FE models where the hot spot stress is always located at the saddle position. For the in-plane bending and out-of-plane bending cases, the percentage difference of the SIFs ranges from $13.1 \%$ to $68.9 \%$ and $-32.9 \%$ to $37.9 \%$ respectively. Hence, the indirect method should be used with caution as it is not always conservative for every case. 


\section{NOMENCLATURES}

$\begin{array}{ll}a & \text { crack depth } \\ c & \text { half crack length } \\ \text { DOB } & \text { degree of bending } \\ d_{0} & \text { chord diameter } \\ d_{1} & \text { brace diameter } \\ H_{\text {cra }} & \text { height of cutting cross-section of the Crack Tube } \\ K & \text { general form of stress intensity factor } \\ K_{\mathrm{I}} & \text { Mode-I stress intensity factor } \\ K_{\mathrm{II}} & \text { Mode-II stress intensity factor } \\ K_{\mathrm{III}} & \text { Mode-III stress intensity factor } \\ l_{0} & \text { chord length } \\ l_{1} & \text { brace length } \\ M_{\mathrm{km}}, M_{\mathrm{kb}} & \text { weld toe magnification factors due to membrane and bending stresses } \\ M_{\mathrm{m}}, M_{\mathrm{b}} & \text { plain plate shape factor for tension and bending } \\ \mathrm{SCF} & \text { stress concentration factor } \\ t_{0} & \text { thickness of the chord of nozzle and CHS T/Y-joint } \\ t_{1} & \text { thickness of the brace of nozzle and CHS T/Y-joint } \\ W_{\text {cra }} & \text { width of cutting cross-section of the Crack Tube } \\ Y_{\mathrm{EQ}} & \text { shape factor calculated from Eq. } 5 \\ Y_{\mathrm{FE}} & \text { shape factor determined from FE analysis } \\ Y(g) & \text { general form of shape factor } \\ \alpha & \text { a ratio of } 2 l_{0} / d_{0} \\ \beta & \text { a ratio of } d_{1} / d_{0} \\ \gamma & \text { a ratio of } d_{0} / 2 t_{0} \\ \theta & \text { intersecting angle between brace and chord } \\ \sigma_{\mathrm{n}} & \text { nominal stress } \\ \tau & \text { a ratio of } t_{1} / t_{0} \\ \phi & \text { crack front angle } \\ & \end{array}$

\section{REFERENCES}

[1] Shivakumar, K.N. and Raju, I.S., "Treatment of Singularities in Cracked Bodies," International Journal of Fracture, 1990, Vol. 45, No. 3, pp. 159-178.

[2] Madia, M., Beretta, S., Schödel, M., Zerbst, U., Luke, M. and Varfolomeev, I., "Stress Intensity Factor Solutions for Cracks in Railway Axles," Engineering Fracture Mechanics, 2011, Vol. 78, No. pp. 764-792.

[3] Hutař, P. and Náhlík, L., "Fatigue Crack Shape Prediction Based on Vertex Singularity," Applied and Computational Mechanics, 2008, Vol. 2, No. pp. 45-52.

[4] Heyder, M., Kolk, K. and Kuhn, G., "Numerical and Experimental Investigations of the Influence of Corner Singularities on 3D Fatigue Crack Propagation," Engineering Fracture Mechanics, 2005, Vol. 72, No. 13, pp. 2095-2105.

[5] Huang, X. and Hancock, J.W., "The Stress Intensity Factors for Semi-elliptical Cracks in a Tubular Welded T-joint Under Axial Loading," Engineering Fracture Mechanics, 1988, Vol. 30, No. 1, pp. 25-35.

[6] Rhee, H.C., "Fatigue Crack Growth Analyses of Offshore Structural Tubular Joints," Engineering Fracture Mechanics, 1989, Vol. 34, No. 5/6, pp. 1231-1239. 
[7] Bowness, D. and Lee, M.M.K., "The Development of an Accurate Model for the Fatigue Assessment of Doubly Curved Cracks in Tubular Joints," International Journal of Fracture, 1995, Vol. 73, No. 2, pp. 129-147.

[8] Bowness, D. and Lee, M.M.K., "Fatigue Crack Curvature under the Weld Toe in an Offshore Tubular Joint," International Journal of Fatigue, 1998, Vol. 20, No. 6, pp. 481-490.

[9] Cao, J.J., Yang, G.J., Packer, J.A. and Burdekin, F.M., "Crack Modeling in FE Analysis of Circular Tubular Joints," Engineering Fracture Mechanics, 1998, Vol. 61, No. 5-6, pp. 537-553.

[10] Lie, S.T., Lee, C.K. and Wong, S.M., "Model and Mesh Generation of Cracked Tubular Y-Joints,” Engineering Fracture Mechanics, 2003, Vol. 70, No. 2, pp. 161-184.

[11] Chiew, S.P., Lie, S.T., Lee, C.K. and Huang, Z.W., "Stress Intensity Factors for a Surface Crack in a Tubular T-Joint," International Journal of Pressure Vessels and Pipes, 2001, Vol. 78, No. 10, pp. 677-685.

[12] Peter, T.M., Corrosion Fatigue and Fracture Mechanics of High Strength Jack Up Steels, $\mathrm{PhD}$ thesis, Department of Mechanical Engineering, University College London, UK, 1998.

[13] Shao, Y.B. and Lie, S.T., "Parametric Equation of Stress Intensity Factor for Tubular K-joint,” International Journal of Fatigue, 2005, Vol. 27, No. 6, pp. 666-679.

[14] BS7910-Amendment 1, Guide to Methods for Assessing the Acceptability of Flaws in Fusion Welded Structures, British Standards Institution, London, UK, 2005.

[15] Newman, J.C. and Raju, I.S., "An Empirical Stress Intensity Factors Equation for the Surface Crack," Engineering Fracture Mechanics, 1981, Vol. 15, No. 1-2, pp. 185-192.

[16] Newman, J.C., Reuter, W.G. and Aveline, C.R., "Stress and Fracture Analysis of Semi-elliptical Surface Cracks," 30 ${ }^{\text {th }}$ National Symposium of Fatigue and Fracture Mechanics, St. Louis, MO, USA, 1998, pp. 403-426.

[17] Lee, M.M.K. and Bowness, D., "Estimation of Stress Intensity Factor Solutions for Weld Toe Cracks in Offshore Tubular Joints," International Journal of Fatigue, 2002, Vol. 24, No. 8, pp. 861-875.

[18] Lie, S.T., Li, T. and Shao, Y.B., "Estimation of Stress Intensity Factors in Tubular K-joints Using Direct and Indirect Methods". International Journal of Advanced Steel Construction, 2012, Vol. 8, No. 2, pp. 17-37.

[19] America Petroleum Institute, Recommended Practice for Planning, Designing and Constructing Fixed Offshore Platforms-Working Stress Design, API-RP-2A-WSD, Washington, USA, 2005.

[20] Lie, S.T., Li, T. and Shao, Y.B., "Plastic Collapse Load Prediction and Failure Assessment Diagram Analysis of Cracked Circular Hollow Section T-joint and Y-joint," Fatigue \& Fracture of Engineering Material \& Structure, 2014, Vol. 37, No. 3, pp. 314-324.

[21] FEACrack ${ }^{\mathrm{TM}}$, User's Manual, Version 3.2, Quest-reliability-LLC, USA, 2003.

[22] ABAQUS, (2009). Standard User's Manual, Version 6.9. Hibbett, Karlsson \& Sorensen, Inc. Providence, Rhode Island, USA.

[23] Ritchie, D., and Huijskens, H.A.M., "Fracture Mechanics Based Prediction of the Effect of Size of Tubular Joint Test Specimens on Their Fatigue Life," The $8^{\text {th }}$ International Conference on Offshore Mechanics and Arctic Engineering, The Hague, Netherlands, 1988, pp. 121-126.

[24] Shen, W. and Choo, Y.S., "Stress Intensity Factor for a Tubular T-joint with Grouted Chord," Engineering Structures, 2012, Vol. 35, pp. 37-47.

[25] Connolly, M.P., Hellier, A.K., Dover, W.D. and Sutomo, J., "A Parametric Study of the Ratio of Bending to Membrane Stress in Tubular Y and T joints," International Journal of Fatigue, 1990, Vol. 12, No. 1, pp. 3-11. 